PONTIFÍCIA UNIVERSIDADE CATÓLICA DO RIO DE JANEIRO

Valuation para determinar o valor da empresa Romão Tecnologias

\author{
Oscar Romão
}

Trabalho de Conclusão de Curso

Centro de clências socials - CCS

DEPARTAMENTO de AdMINISTRAÇÃo

Graduação em Administração de Empresas 
Oscar Romão

\section{Valuation para determinar o valor da empresa Romão tecnologias}

Trabalho de Conclusão de Curso

Trabalho de Conclusão de Curso, apresentado ao programa de graduação em Administração da PUC-Rio como requisito parcial para a obtenção do titulo de graduação em Administração.

Orientador: Luiz Eduardo Brandão 


\section{Agradecimentos}

Foram três anos e meio desde a minha entrada na universidade em 2012, período que vou guardar para sempre em minha memória. Na PUC adquiri o conhecimento que me capacita como Administrador, mas, além disso, tive a oportunidade de conviver com pessoas edificantes, professores, colegas de classe, todo o pessoal do staff, os responsáveis pela limpeza, cada um, que tive o privilégio de conhecer nesse período colaborou nesse processo de crescimento acadêmico e, sobretudo, humano. Despeço-me da universidade com um "até logo" porque tenho certeza que vou voltar. O aluno que entrou em 2012 sai em 2016 com um diploma na mão e uma cabeça cheia de ideias e vontade de fazer a diferença.

Meu maior agradecimento é aos meus grandes incentivadores, que por vezes, fizeram sacrifícios para que eu alcançasse meus objetivos, meu pai Oscar e minha mãe Marilda. Agradeço também ao meu irmão Caio, que sempre me apoiou, fosse com palavras ou atitudes. Agradeço ao meu orientador Luiz Eduardo Brandão, por compartilhar o seu conhecimento e experiência. Ao corpo docente, discente e ao pessoal de apoio da Universidade. E por fim, mas não menos importantes, aos colaboradores da Romão, desde o pessoal do chão de fábrica até o diretor, sem o trabalho diário dessas pessoas esse estudo não seria possível, elas representam o maior valor da empresa. 


\section{Resumo}

Romão, Oscar. Valuation para determinar o valor da empresa Romão tecnologias. Rio de Janeiro, 2016. Trabalho de Conclusão de Curso Departamento de Administração. Pontifícia Universidade Católica do Rio de Janeiro.

Este trabalho consiste em fazer uma avaliação de mercado da empresa Romão tecnologias utilizando o método do fluxo de caixa descontado. Analisando o ambiente interno e externo, projetamos os fluxos de caixas futuros e descontamos esses fluxos a uma taxa, determinada através do custo médio ponderado de capital, para chegarmos a um valor justo da empresa Romão Tecnologias.

Palavras- chave:

Custo do capital próprio, Custo do capital de Terceiros, Custo médio ponderado de capital, Estrutura de capital, Valuation, Fluxo de caixa descontado

\section{Abstract}

Romão, Oscar. Valuation para determinar o valor da empresa Romão tecnologias. Rio de Janeiro, 2016. Trabalho de Conclusão de Curso Departamento de Administração. Pontifícia Universidade Católica do Rio de Janeiro.

This work is to make a market valuation of the company Romao technologies using the method of discounted cash flow .Analyzing the internal and external environment, we project future cash flows and we discount these flows at a rate determined by the weighted average cost of capital, to arrive at a fair value of Romao

Key-words:

Cost of Equity, Cost of Debt, WACC, Capital structure, Valuation, Discounted Cash Flow. 


\section{Sumário}

1. Introdução 1

2. Contextualização 3

2.1. O mercado de petróleo e gás 3

2.2. O mercado sucroenergético 6

2.3. Nicho de mercado de armazenamento do etanol e do petróleo e $\begin{array}{ll}\text { seus derivados } & 7\end{array}$

2.4. Os equipamentos de segurança para operação dos tanques 8

3. Referencial Teórico 10

3.1. Modelo do fluxo de caixa descontado 10

3.1.1. Custo do capital próprio (ke) 11

3.1.1. Taxa livre de risco (Rf) 11

3.1.1.2. Prêmio de risco de mercado 11

3.1.1.3. $O$ índice beta $(\boldsymbol{\beta}) \quad 12$

3.1.1.3.1. O índice de beta desalavancado ( $\beta \mathrm{u})$

3.1.1.3.2. O índice de beta alavancado $(\beta \mathrm{I}) \quad 12$

3.1.2. Custo de capital de terceiros (Kd) 13

3.1.3. Estrutura de Capital 13

3.1.4. Custo médio ponderado de capital (WACC) 13

3.1.5 Perpetuidade com crescimento 14

3.1.6. O Efeito Fisher Internacional 14

$\begin{array}{ll}\text { 4. A Empresa } & 15\end{array}$

5. Avaliação da empresa 18

5.1. Considerações iniciais 18

5.2. Projeção do fluxo de caixa 19

5.2.1 Projeção da Receita 19

5.2.2 Projeção dos custos dos produtos / serviços vendidos 21

5.2.3. Projeção dos Gastos com pessoal 22

5.2.4. Projeção das Despesas operacionais 22 
5.2.5. Projeção das Despesas de venda 22

5.2.6. Projeção das Despesas financeiras e com depreciação 23

5.2.7 Projeção do fluxo de caixa livre 23

5.3 Taxa de desconto 24

5.3.1 custo do capital de terceiros 24

5.3.2 custo do capital próprio 24

5.3.2.1 Custo do capital próprio nos Estados Unidos 25

5.3.3 Custo médio ponderado de capital (WACC) 26

5.4. O Valor da empresa 27

5.4.1. O Valor da perpetuidade 27

5.4.2. O valor do fluxo de caixa projetado nos cenários 28

5.4.3. O Valor líquido da empresa 28

6. Conclusão e Recomendação 30

7. Referências Bibliográficas 32

8. Anexos 33

8.1. Demonstrações de Resultado 33

8.2. Balanço Patrimonial 201534

8.3. Beta desalavancado do setor (Dados do site do economista Answath Damodaran, janeiro/2016) 35

8.4. Prêmio de risco e taxa livre de risco (Dados do site do economista Answath Damodaran, janeiro/2016) 36

8.5.0 Risco Brasil (Dados do site do economista Answath Damodaran, janeiro/2016) 36

8.6. Projeção de resultado - Cenário pessimista 37

8.7. Projeção de resultado - Cenário Realista (Cenário Base) 38

8.8. Projeção de resultado - Cenário Otimista 39

8.9. Projeção do Bradesco de longo prazo para economia Brasileira40 8.10 Organograma da Romão 41

8.11. Infraestrutura de produção e movimentação do petróleo e seus derivados 42

8.12. Produtos Romão 43 


\section{Lista de Tabelas}

Tabela 1 - Capacidade de armazenamento de petróleo e derivados de etanol.

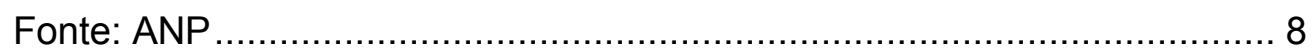

Tabela 2 - Tabela das alíquotas no Lucro presumido .................................... 18

Tabela 3 - Margem dos produtos / serviço .................................................. 21

Tabela 4 - Projeção do fluxo de caixa nos 3 cenários ..................................... 23

Tabela 5 - Custo do capital de terceiros (Kt) ............................................... 24

Tabela 6 - Beta desalavancado do setor de equipamentos e serviços para o

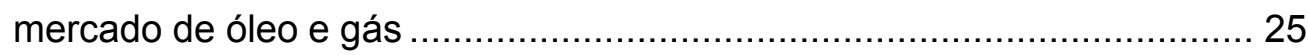

Tabela 7 - Beta alavancado da Romão....................................................... 25

Tabela 8 - Custo do capital próprios nos EUA (Ks) ...................................... 26

Tabela 9 - Custo do capital próprio no Brasil ............................................. 26

Tabela 10 - Custo médio ponderado de capital da Romão .............................. 27

Tabela 11 - Valor presente da perpetuidade ............................................. 27

Tabela 12 - VPL da empresa nos três cenários ............................................ 28

Tabela 13 - Valor da empresa considerado a probabilidade de cada cenário.... 28

Tabela 14 - Valor líquido da empresa........................................................... 29

\section{Lista de Figuras}

Figura 1 - Investimentos em exploração e produção e preço do petróleo. Fonte:

IBP 4

Figura 2 - Evolução da capacidade de refino. Fonte: ANP............................... 5

Figura 3 - A cadeia produtiva de cana da cana de açúcar por Neves e Trombin

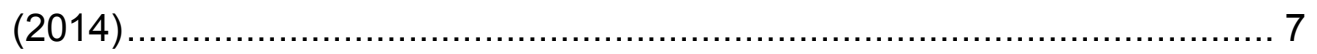

Figura 6 - Evolução do preço do barril de petróleo Fonte ANP ...................... 16

Figura 7 - Índice de confiança da indústria. Fonte: FGV .............................. 20 


\section{Introdução}

Esse trabalho tem como objetivo determinar o valor da empresa Romão tecnologias utilizando o modelo do fluxo de caixa descontado. $O$ trabalho de Valuation é uma oportunidade de analisar a empresa e o seu mercado de atuação e tangibilizar essa análise através de projeções financeiras, que podem servir para o planejamento e controle gerenciais. $O$ trabalho também vai auxiliar na elaboração das estratégias da empresa no intuito de maximizar o seu valor. Conhecer o custo do capital da empresa vai ser uma importante ferramenta para análise de investimento. E por fim, conhecer o valor da empresa vai permitir aos acionistas uma eventual negociação de forma mais justa.

A Romão é uma empresa familiar fundada em 1978 que fabrica e repara equipamentos de segurança para a operação de armazenamento de fluidos voláteis. A empresa possui um escritório em Nova Iguaçu onde são desempenhadas as atividades administrativas, uma fábrica em Macaé e está em fase final de construção a unidade no município de Japeri, onde se pretende unificar toda operação, administrativo e fabricação.

Os resultados indicam que a empresa tem um valor líquido de $\mathrm{R} \$$ 10.796.806. Esse valor líquido de dívidas pode variar entre cinco até vinte e quatro milhões de reais, dependendo do cenário considerado, indicando a volatilidade e o risco do negócio. O resultado ficou de acordo com a expectativa dos acionistas e do mercado, tendo como base de comparação a venda da ASCA, empresa de São Paulo, com o mesmo porte da Romão que atua em mercado similar, ocorrida em 2010 por quinze milhões de reais.

Esse trabalho está organizado em seis capítulos. Após essa introdução, no capítulo dois, pretende-se contextualizar o mercado de atuação da empresa, analisando as cadeias produtivas do mercado de óleo e gás e sucroenergético, até $\mathrm{o}$ armazenamento desses produtos em tanques que precisam de equipamentos para garantir a segurança da operação.

No capítulo três, será apresentado o referencial teórico que serviu de suporte para elaboração do estudo. O conceito de fluxo de caixa descontado, custo de capital e perpetuidade e sua aplicação no objeto de estudo. 
No quarto capítulo, a empresa será apresentada, contando toda sua trajetória, analisando seus pontos fortes e fracos e contextualizando com o mercado.

No quinto capítulo será aplicado o Valutaion, pelo modelo do fluxo de caixa descontado. Serão projetados fluxos de caixa em três cenários diferentes: Recessão, estabilidade e crescimento. Posteriormente, será calculado o custo do capital da empresa, levando-se em consideração a estrutura de capital e o custo do capital próprio e de terceiros. O valor final da empresa deve ser obtido descontando os fluxos de caixa futuros pelo custo do capital da empresa.

Por fim, o resultado obtido vai ser analisado pela perspectiva do acionista e do mercado e serão recomendadas ações no intuito de maximizar o valor da empresa. 


\section{Contextualização}

Nesse capítulo serão analisados os dois mercados de atuação da Romão: óleo e gás e sucroenergético. Será apresentado um breve histórico com uma análise das características de cada mercado, sobre os principais concorrentes, as margens, as barreiras de entrada, o panorama atual e as perspectivas futuras.

Depois dessa apresentação vai ser abordado o processo de armazenamento desses combustíveis. A Romão fabrica os equipamentos que garantem a segurança dessa operação, portanto será realizada uma análise específica sobre o processo de armazenamento na cadeia produtiva do etanol e do petróleo e seus derivados.

Por fim, serão apresentados os equipamentos que a Romão fabrica, a função desses equipamentos no tanque, seu funcionamento e as normas de fabricação e operação.

\subsection{O mercado de petróleo e gás}

O primeiro poço de petróleo comercialmente explorável no país foi descoberto em 1939 em Salvador, hoje o país é um dos maiores produtores e no futuro poder se tornar um grande player mundial no mercado de óleo e gás. O setor representou 13\% do PIB (produto interno bruto brasileiro) em 2014 segundo dados divulgados pelo IBGE (Instituto Brasileiro de Geografia e Estatística).

O paradigma da verticalização das atividades de petróleo, que marcou fortemente sua trajetória ao longo de um século, vem sendo desfeito, com empresas desfazendo-se de elos importantes de suas cadeias de suprimento e adotando a prática da terceirização. Borges (2000).

O setor de óleo e gás pode ser dividido em 3 grandes grupos: EeP (Exploração e Produção), Refino e Distribuição.

O segmento de EeP se destaca como maior indutor de investimentos, as características de exploração e produção demandam capital intensivo, alta tecnologia e inovação. Após um período de estagnação de investimentos nessa 
área, até o início da década de 2000, a partir desse período os investimentos aumentaram significativamente acompanhando o aumento do preço do barril de petróleo, fatores internos como a quebra do monopólio da Petrobras em 1997 e a instituição do REPETRO (regime fiscal especial para o setor petrolífero) em 1999 também contribuíram para atração de investimento, mas o maior catalisador de fluxo de investimento foi a descoberta do pré-sal a partir de 2006. Na figura 1 podemos acompanhar a relação do preço do barril do petróleo com os investimentos em exploração e produção.

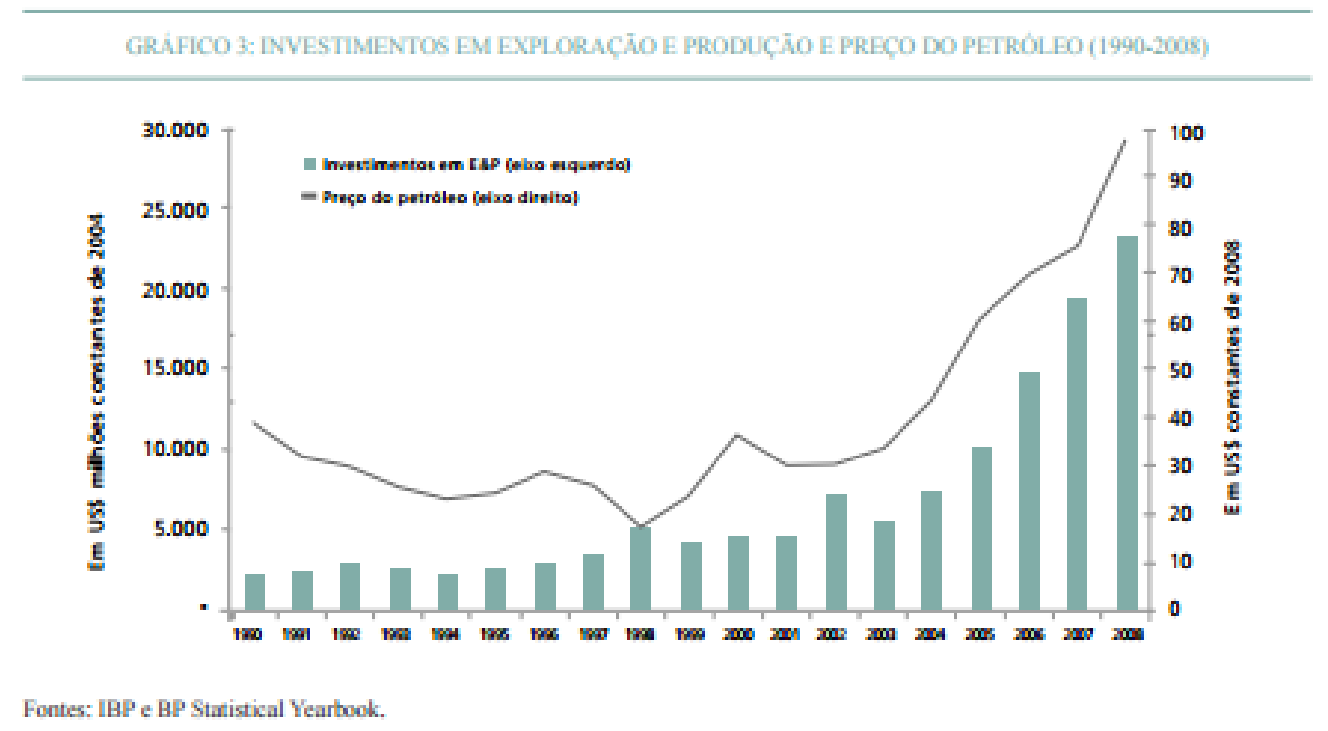

Figura 1 - Investimentos em exploração e produção e preço do petróleo. Fonte: IBP

O segmento de Refino é o responsável por transformar o óleo bruto em produtos para a aplicação da população como Nafta, gasolina, diesel e outros derivados. Enquanto o país concentrou esforços em descoberta e exploração de novos poços, a capacidade de refino não acompanhou o crescimento da demanda e tornou-se um gargalo na cadeia produtiva do petróleo. Atualmente o país possui 13 refinarias com capacidade de produção de dois milhões de barris de derivado de petróleo por dia, segundo dados da ANP (2015), esse montante não é suficiente para atender a demanda interna, o que obriga o país a importar, para diminuir a dependência do mercado exterior e resolver esse gargalo na cadeia produtiva, o país busca ampliar sua capacidade com a construção de novas refinarias e no aumento da produtividade das refinarias existentes. A tabela 1 demonstra a evolução na capacidade de refino de 2005 até 2014 . 


\begin{tabular}{|c|c|c|c|c|c|c|c|c|c|c|}
\hline \multirow{2}{*}{$\begin{array}{c}\text { Refinarias } \\
\text { (Unidade da Federaçäo) } \\
\end{array}$} & \multicolumn{10}{|c|}{ Capacidade de refino (barrilfdia) } \\
\hline & 2005 & 2006 & 2007 & 2008 & 2009 & 2010 & 2011 & 2012 & 2013 & 2014 \\
\hline Total' & 2.044 .054 & 2.044 .054 & 2.063 .552 & 2.076 .604 & 2.092 .643 & 2.092 .643 & 2.115 .859 & 2.105 .795 & 2.203 .287 & 2.352 .262 \\
\hline Riograndense (RS) & 16.983 & 16.983 & 16.983 & 16.983 & 16.983 & 16.983 & 17.014 & 17.014 & 17.014 & 17.014 \\
\hline Lubnor (CE) & 6.919 & 6.919 & 6.919 & 8.177 & 8.177 & 8.177 & 8.177 & 8.177 & 8.177 & 8.177 \\
\hline Manguinhos (RJ) & 13.838 & 13.838 & 13.838 & 13.838 & 13.838 & 13.838 & 13.838 & 13.838 & 13.838 & 13.838 \\
\hline Recap (SP) & 53.463 & 53.463 & 53.463 & 53.463 & 53.463 & 53.463 & 53.463 & 53.463 & 53.463 & 53.463 \\
\hline Reduc (RJ) & 242.158 & 242.158 & 242.158 & 242.158 & 242.158 & 242.158 & 242.158 & 242.158 & 242.158 & 242.158 \\
\hline Refap (RS) & 188.695 & 188.695 & 188.695 & 188.695 & 188.695 & 188.695 & 201.274 & 201.274 & 201.274 & 201.274 \\
\hline Regap (MG) & 150.956 & 150.956 & 150.956 & 150.956 & 150.956 & 150.956 & 150.956 & 150.956 & 150.956 & 166.051 \\
\hline Reman (AM) & 45.916 & 45.916 & 45.916 & 45.916 & 45.916 & 45.916 & 45.916 & 45.916 & 45.916 & 45.916 \\
\hline Repar (PR) & 188.695 & 188.695 & 201.274 & 220.144 & 220.144 & 220.144 & 220.144 & 207.564 & 207.564 & 207.564 \\
\hline Replan (SP) & 364.810 & 364.810 & 364.810 & 383.679 & 415.128 & 415.128 & 415.128 & 415.128 & 415.128 & 433.998 \\
\hline Revap (SP) & 251.593 & 251.593 & 251.593 & 251.593 & 251.593 & 251.593 & 251.593 & 251.593 & 251.593 & 251.593 \\
\hline Rilam $(B A)^{2}$ & 322.982 & 322.982 & 322.982 & 295.307 & 279.897 & 279.897 & 279.897 & 279.897 & 377.389 & 377.389 \\
\hline $\mathrm{RPBC}(\mathrm{SP})$ & 169.825 & 169.825 & 169.825 & 169.825 & 169.825 & 169.825 & 169.825 & 169.825 & 169.825 & 169.825 \\
\hline $\operatorname{RPCC}(\mathrm{RN})$ & 27.222 & 27.222 & 27.222 & 27.222 & 27.222 & 27.222 & 35.223 & 37.739 & 37.739 & 37.739 \\
\hline Rinest (PE) & . & . & . & . & . & . & . & . & . & 115.009 \\
\hline Univen (SP) & . & . & 6.919 & 6.919 & 6.919 & 6.919 & 9.158 & 9.158 & 9.158 & 9.158 \\
\hline Dax Dil (BA) & . & . & . & 1.730 & 1.730 & 1.730 & 2.095 & 2.095 & 2.095 & 2.095 \\
\hline Total' (barriltdia- & 1.941 .851 & 1.941 .851 & 1.960 .375 & 1.972 .774 & 1.988.011 & 1.988.011 & 2.010 .066 & 2.000 .505 & 2.093 .123 & 2.234 .648 \\
\hline Fator de Utilizaçãos $[\%]$ & 89.6 & 90.3 & 91,1 & 89.9 & 91,1 & 91,2 & 92.8 & 96.3 & $\mathbf{9 8 . 2}$ & 94.3 \\
\hline
\end{tabular}

Figura 2 - Evolução da capacidade de refino. Fonte: ANP.

O segmento de distribuição é o último da cadeia produtiva da indústria de óleo e gás, através dos modais dutoviário, ferroviário, rodoviário e marítimo os derivados de óleo e gás chegam até o consumidor final. No Brasil há uma predominância nos modais rodoviários e ferroviários, que elevam o custo em comparação com o modal dutoviário. Por ser a última etapa da cadeia produtiva, a distribuição está diretamente relacionada à capacidade de refino do país, embora atualmente ela seja capaz de atender a necessidade, uma expansão da capacidade de refino do país vai demandar investimentos em distribuição.

A indústria do petróleo é reconhecida por elevados níveis de certificação requeridos em suas atividades. Para atender a esses requisitos as empresas da cadeia produtiva de petróleo tem que priorizar a qualidade e segurança de suas soluções.

Um fator que coloca os fornecedores brasileiros em destaque é a política de conteúdo local, inspirado no bem sucedido modelo Norueguês que buscou uma integração entre políticas públicas e inciativa privada para o desenvolvimento do setor de óleo e gás. A política de conteúdo local estabelece por contrato a necessidade de se atingir um percentual de conteúdo local mínimo, dessa maneira há um direcionamento para aquisição de bens e serviços de empresas nacionais. O objetivo dessa política é incentivar o aumento da capacidade produtiva nacional, contudo as empresas nacionais precisam se qualificar para atender a um mercado extremamente exigente e técnico. 


\subsection{O mercado sucroenergético}

Historicamente a cana de açúcar sempre teve papel de destaque na economia do país, ainda hoje o Brasil se mantém como o maior produtor do mundo. Da matéria-prima, a cana-de-açúcar, produzem-se açúcar, álcool anidro (aditivo para gasolina), álcool hidratado e bioenergia.

O Brasil conta com quase 400 usinas de açúcar e etanol, de acordo com a ANP (2015), a maior parte delas fica na região centro-sul especialmente no interior de São Paulo.

O atual momento de incertezas, seguidas safras ruins, aumento estrutural dos custos e intervenção do governo no preço da gasolina, fizeram as margens do setor despencar e o nível de endividamento das empresas crescer. Esses fatores contribuíram para uma onda de fusões e aquisições, com muitos investidores externos adquirindo grupos em dificuldade. Apesar das dificuldades, os principais fundamentos que moldam o futuro do setor persistirão no horizonte considerado nas perspectivas dos investimentos 2015-2018 e panoramas setoriais do BNDES (2014): Crescimento da frota de veículos flex, o que aumenta a demanda por etanol e as pressões ambientais que forçam o governo a adotar medidas que mitiguem os efeitos negativos da atividade produtiva do petróleo e seus derivados, nesse contexto tanto o etanol como a produção bioenergética a partir da cana se apresentam como soluções atrativas.

A grandeza econômica do setor é demonstrada por Neves e Trombin (2014) que estimaram o PIB gerado pela cadeia sucroenergética em US\$ 43,36 bilhões na safra 2013-2014. Esse valor equivaleu a aproximadamente 2\% do PIB brasileiro de 2013.

Diferentemente do setor de óleo e gás cuja exigibilidade de certificação é alta e a cadeia produtiva conta com diversos players externos, a cadeia produtiva do setor sucroenergético é dominada quase que na sua totalidade por empresas nacionais. Segundo Neves e Trombin-- (2014), o faturamento bruto com a venda de bens de capital para a cadeia sucroenergética, que conta com máquinas e implementos agrícolas e equipamentos industriais, foi de US\$ 4,6 bilhões na safra 2013-2014. Apesar disso, a entrada de investidores externos, bem como a modernização das empresas do setor , fez aumentar a exigibilidade técnica e de segurança nos últimos anos seguindo os parâmetros da indústria de petróleo e gás. 


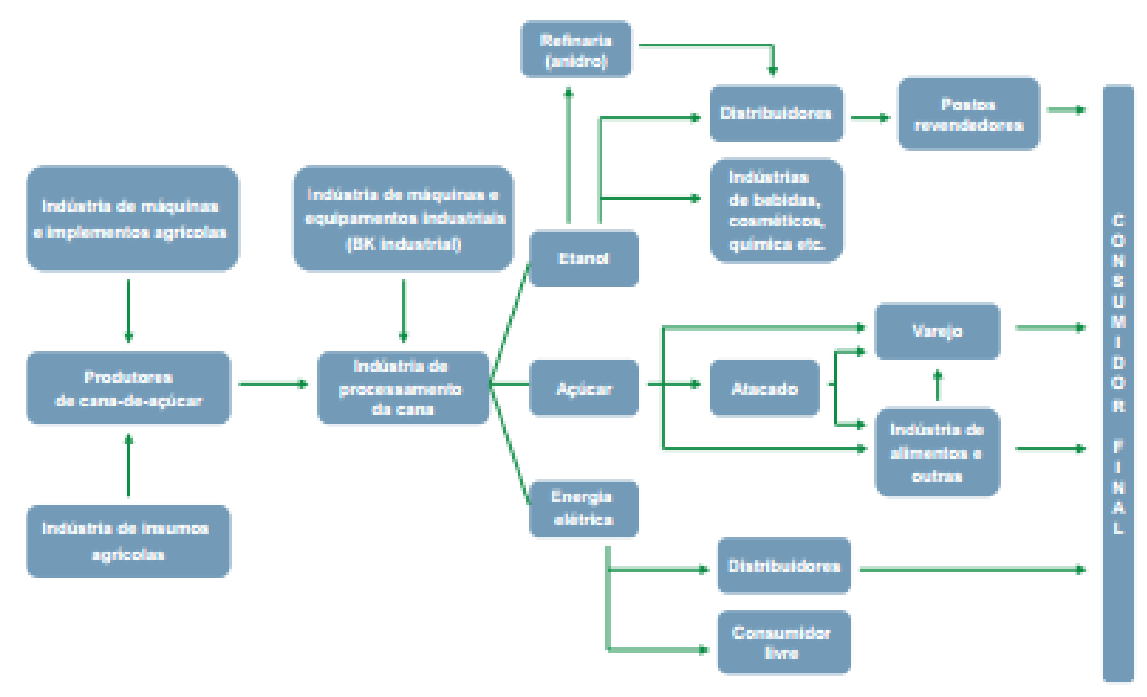

Figura 3 - A cadeia produtiva de cana da cana de açúcar por Neves e Trombin (2014)

\subsection{Nicho de mercado de armazenamento do etanol e do petróleo e seus derivados}

Durante as etapas de refino e distribuição dos derivados de petróleo e do etanol a estocagem é feita em tanques de armazenamento, que podem ter as mais variadas formas e tamanhos, dependendo do tipo do fluido armazenado e da etapa de produção/distribuição. A construção desses tanques é regulamentada pela norma americana API 650, sendo que o formato mais comum é o cilíndrico vertical que pode atingir mais de 60 metros de diâmetro. Para o armazenamento de gases, no entanto, utiliza-se a forma redonda com intuito de anular as pressões internas do gás armazenado.

O Brasil possui 1939 tanques de armazenamento capazes de armazenar até 13.425.401 metros cúbicos de petróleo, etanol e seus derivados conforme dados divulgados no anuário estatístico da ANP (2015). 


\begin{tabular}{|l|c|c|}
\hline \multirow{2}{*}{$\begin{array}{c}\text { Tipo, local e operador (Unidade da } \\
\text { Federação). }\end{array}$} & \multicolumn{2}{|c|}{$\begin{array}{c}\text { Capacidade de armazenamento de } \\
\text { petróleo, seus derivados e etanol. }\end{array}$} \\
\cline { 2 - 3 } & $\begin{array}{c}\text { Número de } \\
\text { tanques }\end{array}$ & $\begin{array}{c}\text { Capacidade nominal } \\
\left(\mathrm{m}^{3}\right)\end{array}$ \\
\cline { 3 - 3 } & 1.939 & Total $^{3}$ \\
\hline Total & 21 & 13.425 .401 \\
\hline Centro Coletor de Etanol & 1.442 & 105.000 \\
\hline Terminal Aquaviário & 476 & 9.344 .158 \\
\hline Terminal Terrestre & & 3.976 .242 \\
\hline
\end{tabular}

Tabela 1 - Capacidade de armazenamento de petróleo e derivados de etanol. Fonte: ANP

\subsection{Os equipamentos de segurança para operação dos tanques}

Por se tratar de produtos altamente inflamáveis e caros, o armazenamento é feito obedecendo a uma série de normas e procedimentos. Para a segurança da operação, nesses tanques é obrigatória a instalação do equipamento VAPV (válvula de alívio de pressão e de vácuo) que faz alívio da pressão positiva ou negativa impedindo que o tanque murche ou exploda. Existe também o Selo Película (item 8.12 nos anexos), uma construção metálica, geralmente em alumínio, que "boia" sob o líquido armazenado, como se fosse um "teto interno flutuante". Como essa película fica sempre em contato com o líquido, reduz as pressões internas e evita as perdas por evaporação, o que do ponto de vista econômico é benéfico para o cliente e faz com que o equipamento se pague em poucos meses. Outro equipamento de segurança também utilizado é o CortaChamas (item 8.12 nos anexos), que impede a propagação de chamas para dentro do tanque, o que pode ocorrer durante o processo esvaziamento ou enchimento do tanque, uma vez que nesse momento pode ocorrer a entrada de oxigênio faltando apenas uma fagulha para fechar o triângulo do fogo, o que pode ocorrer em função de um raio, por exemplo.

A fabricação e operação de todos esses produtos são regulamentadas por rígidas normas internacionais, como a API 2000, EN12874 e a API650. No entanto, no Brasil não existiam laboratórios aptos a fazer essa certificação, o que fazia com que fosse necessário enviar o produto para laboratórios nos EUA ou Europa. O custo de um processo de certificação no exterior pode chegar a U\$ 
$100.000,00$ por equipamento, sendo que o prazo pode variar de 12 a 24 meses.

No caso do equipamento não ser aprovado, todo o investimento é perdido. 


\section{Referencial Teórico}

Avaliar o valor de um ativo tem sido objeto de estudo de diversos autores, existem diversos modelos apoiados em premissas, conceitos econômicos e financeiros e também em aspectos intangíveis. Nesse estudo iremos utilizar o modelo de fluxo de caixa descontado e nos basear principalmente nos autores Damodaran, Titman, Ross, Westerfield, Jordan e Martin. O modelo se apoia na análise de demonstrativos financeiros, dados históricos, macro e microambiente, para projeção de fluxos de caixa futuros descontados a uma taxa, que é o custo de capital da empresa.

COPELAND, KOLLER e MURRIN (2004) afirmam que o aumento da importância dos acionistas nos mercados levou uma crescente quantidade de administradores a concentrar-se na criação de valor como sendo a medida mais importante do desempenho corporativo.

\subsection{Modelo do fluxo de caixa descontado}

Nos modelos baseados em fluxo de caixa descontado, o valor da empresa é uma função dos fluxos de caixa estimados trazidos a valor presente.

A aplicação desse modelo consiste em estimar os fluxos de caixa relevantes futuros, determinar uma taxa de desconto e trazer esses fluxos futuros a valor presente. As principais dificuldades do modelo estão em determinar os fluxos de caixa futuros frente às incertezas relativas ao macro e micro ambiente e determinar a taxa de desconto.

Tratando-se de avaliação de empresas, para determinar a taxa de desconto dos fluxos de caixa futuros, utiliza-se o custo médio ponderado de capital da empresa, que leva em consideração o custo do capital próprio, o custo do capital de terceiros e a estrutura de capital.

Damodaran (2007) descreve os quatro fatores determinantes para o valor de uma empresa.

"O valor de uma empresa é determinado por quatro fatores - sua capacidade de caixa a partir dos ativos já instalados, a taxa de crescimento 
esperada desses fluxos de caixa, o tempo transcorrido até a empresa alcançar o crescimento estável e o custo de capital".

\subsubsection{Custo do capital próprio (ke)}

O método do CAPM (capital asset pricing model) é utilizado para o cálculo do custo do capital próprio, o modelo divide o risco total de um ativo em dois: risco sistemático (conjuntural ou não diversificável) e risco não sistemático (próprio ou diversificável). O risco sistêmico é aquele imposto a todo ativo pelos sistemas econômicos, políticos e sociais. O risco não sistemático é intrínseco ao ativo e ao subsistema ao qual ele está ligado. O modelo CAPM pode ser escrito matematicamente:

$$
\begin{aligned}
& E(\mathbf{R d})=\mathbf{R f}+\boldsymbol{\beta d}[\mathbf{E}(\mathbf{R m})-\mathbf{R f}] \\
& \text { Onde: } \\
& E(R d)=\text { Retorno esperado do ativo } d \\
& R f=\text { Retorno esperado de um ativo livre de risco } \\
& \beta d=\text { Coeficiente beta do ativo } d
\end{aligned}
$$

\subsubsection{Taxa livre de risco (Rf)}

A taxa livre de risco é a taxa de retorno esperada de um ativo sem risco. COPELAND, KOLLER e MURRIN (2004) defendem a utilização dos títulos da dívida do governo americano como uma aproximação razoável para determinar a taxa livre de risco: (i) o retorno das letras do tesouro americano (treasure bills), (ii) a taxa dos títulos americanos (bonds) de dez anos, e (iii) a taxa dos títulos americanos de trinta anos. No caso de empresas com prazo indeterminado de existência, recomenda-se o uso dos títulos de mais longa maturidade ( $T$-bonds trinta anos) como taxa livre de risco.

\subsubsection{Prêmio de risco de mercado}

O prêmio de risco de mercado é o quanto o investidor exige de retorno para aplicar em ativos que tenham risco. Ross, Westerfield e Jordan (2010) definem prêmio de risco como o retorno excedente exigido de um investimento em um ativo com risco em relação àquele exigido de um investimento sem risco. Damodaran (2007) defende a utilização da diferença entre o retorno esperado no mercado acionário e o retorno da taxa livre de risco. O risco país, utilizado para 
classificar o risco geral de um país é um indicador de prêmio de risco. Para o Brasil e outros mercados emergentes Damodaran (2007) recomenda a utilização do $\mathrm{EMBI}+$ (Emerging Markets Bond Index Plus), calculado pelo banco de investimento americano J. P. Morgan, esse índice é calculado obtendo a média ponderada dos prêmios pagos por títulos brasileiros em relação a papéis de prazo equivalente do Tesouro dos Estados Unidos.

\subsubsection{3. $O$ índice beta $(\beta)$}

Brealey-Meyers-Allen (2008) o índice beta mede a sensibilidade de um ativo em relação em relação ao comportamento de uma carteira que represente o mercado, é, portanto, uma medida de risco, quanto maior o índice beta do ativo, maior sua variabilidade, portanto, maior o risco. Para calcular o Beta, são necessários dados históricos do mercado e do setor da empresa que se pretende avaliar. Como o mercado brasileiro acionário é deficiente de uma série histórica confiável e muito concentrado, Damodaran (2007) recomenda a utilização de dados do mercado norte americano.

\subsubsection{1. $O$ índice de beta desalavancado $(\beta u)$}

O índice beta desalavancado é o indicador de risco do negócio sem as dívidas. Representa, portanto, o risco relativo à operação da empresa sem considerar sua estrutura de capital. Empresas que atuam no mesmo setor possuem betas desalavancados muito próximos, portanto, podem ser utilizadas como aproximação quando há carência de dados confiáveis sobre o beta da empresa em avaliação.

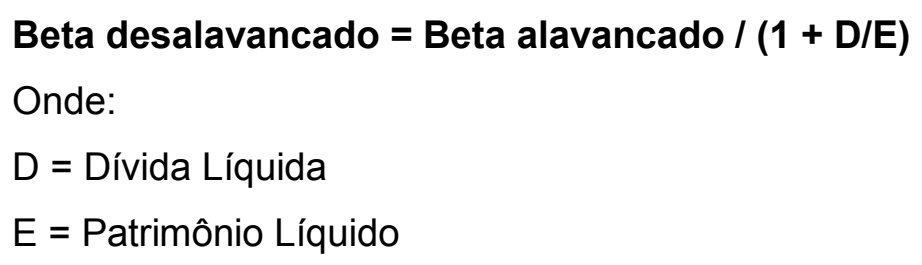

\subsection{O índice de beta alavancado ( $\beta I)$}

O beta alavancado é obtido quando o risco da dívida é incorporado ao risco da atividade, é, portanto, o indicador utilizado para o cálculo do CAPM, porque considera o risco total do ativo. 


\subsubsection{Custo de capital de terceiros (Kd)}

O custo do capital de terceiros é segundo Ross, Westerfield e Jordan (2010) uma relação direta do risco de inadimplência de uma empresa e a taxa básica de juros da economia, quando um desses fatores se eleva, eleva o custo do capital de terceiros. Podemos calcular o custo do capital de terceiros de uma empresa fazendo uma média ponderada das taxas de juros de seus financiamentos.

\subsubsection{Estrutura de Capital}

A estrutura de capital da empresa é a distribuição do capital da empresa, quanto dele é formado por capital próprio e quanto por capital de terceiros. Ross, Westerfield e Jordan (2010) referem-se à alavancagem financeira como o quanto uma empresa se apoia na dívida, quanto mais alavancada a empresa, maior a proporção de capital de terceiros, eles defendem que a estrutura de capital ótima, ou meta, é aquela que resulta no menor custo de capital.

\subsubsection{Custo médio ponderado de capital (WACC)}

O custo médio ponderado de capital da empresa leva em consideração o custo do capital próprio, o custo do capital de terceiros e a estrutura de capital da empresa. Davis e Pointon (1996) exemplificam que para obter o WACC deve-se obter o custo de cada fonte de capital, ponderado por sua respectiva participação na estrutura de financiamento da empresa. Podemos escrever o WACC matematicamente:

$$
\begin{aligned}
& \text { WACC }=\text { Ke } \times \text { E/V + Kd } \times \text { D/V } \\
& \text { Onde: } \\
& \text { Ke = custo do capital próprio } \\
& K d=\text { custo da dívida líquido } \\
& E=\text { Patrimônio Líquido } \\
& V=\text { Valor da empresa } \\
& D=\text { Dívida }
\end{aligned}
$$




\subsubsection{Perpetuidade com crescimento}

Ross, Westerfield e Jordan (2010) definem perpetuidade como uma série de pagamentos na qual os fluxos de caixa ocorrem indefinidamente. Damodaran (2007) defende que toda empresa têm uma fase de crescimento extraordinário sucedido por uma fase de crescimento constante, isso porque seu porte acaba sendo uma barreira para o seu crescimento e alto crescimento com geração de valor implica em altos retornos, o que atrai maior concorrência que acabam eliminando os retornos excessivos. Ross, Westerfield e Jordan (2010) defendem duas maneiras de calcular a taxa de crescimento (g): Usar um histórico dos crescimentos, ou usar previsões de analistas para as taxas de crescimento futuras. A fórmula da perpetuidade com crescimento:

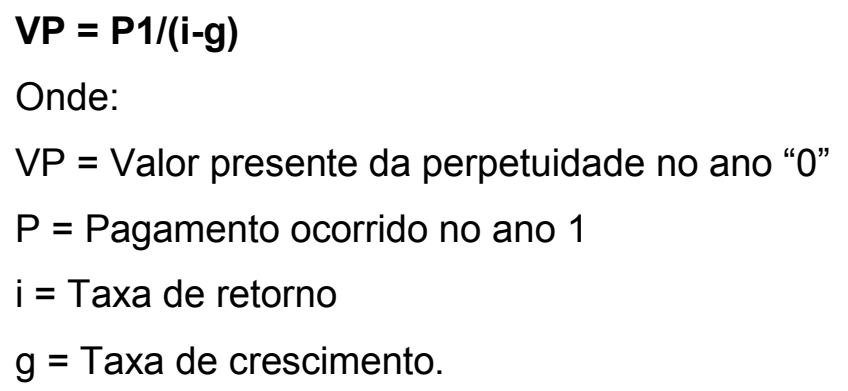

\subsubsection{O Efeito Fisher Internacional}

Ross, Westerfield e Jordan (2010) definem o efeito Fisher internacional como a teoria de que as taxas de juros reais são iguais em todos os países. Pela teoria de Fisher, para determinar a taxa de juros real, que é igual em todos os países, devemos retirar o efeito da inflação. A fórmula de Fisher:

$$
\begin{aligned}
& \text { ir }=(\mathbf{i}+1) /(\text { inf }+1)-1 \\
& \text { Onde: } \\
& \text { ir = Taxa de juros real } \\
& \text { i = Taxa de juro nominal } \\
& \text { inf = Taxa de inflação }
\end{aligned}
$$




\section{A Empresa}

Nos anos 60, Oscar Oliveira era um jovem engenheiro que trabalhava na Varec, uma empresa americana que fabricava VAPV`s. O mercado brasileiro era incipiente e o principal cliente era a recém-criada Petrobras. A Varec encerrou a suas atividades no país nos anos 70 , no mesmo ano em que a Petrobras fez sua maior descoberta de reserva petrolífera até então, a Bacia de Campos. Oscar viu ali uma oportunidade, aproveitando seu know-how do produto e do mercado e comprou um torno mecânico, uma furadeira de bancada, um esmeril e começou na garagem de sua casa a Oscar Oliveira LTDA, que posteriormente foi rebatizada de Valeq (Válvulas e equipamentos industriais LTDA).

Em 1995 com a estabilização do Real como moeda e sob o comando da segunda geração da família, a empresa estava preparada para alçar voos mais altos. A empresa implantou um sistema de qualidade, adquiriu novas máquinas e aumentou seu portfólio de produtos. Nos anos 2000 a empresa cresceu rapidamente, puxada principalmente pelo setor sucroalcooleiro, a Valeq se tornou a principal fornecedora das usinas de etanol, enquanto viu sua participação de mercado no setor de óleo e gás encolher em razão de não ter as certificações exigidas pelo mercado. Em 2006 a Petrobras anunciou as descobertas das reservas do pré-sal apontando para um horizonte promissor, mas a falta de certificação dos produtos se tornou uma barreira de entrada para a empresa no lucrativo setor de óleo e gás.

Em função disso, e devido ao alto custo da certificação no exterior, em 2007 o CEO Oscar Romão decide construir os seus próprios laboratórios, contratando um físico especialista no mercado para gerir a parte de pesquisa e desenvolvimento. Em parceria com o DNV (Det Norsk Veritas), empresa norueguesa líder mundial em serviços de certificação, coloca em prática o projeto de ter o primeiro laboratório brasileiro apto a certificar equipamentos VAPV`s, Corta-chamas e Selo película no país.

Em 2010 é inaugurada a filial em Macaé, um galpão de $4.000 \mathrm{~m} 2$ ao lado da Petrobras unidade de Cabiúnas, com o objetivo de ficar mais próximo do seu principal cliente, num momento em que a Petrobras anunciava um significativo 
plano de investimento com empreendimentos como o Comperj (Complexo petroquímico do Rio de Janeiro), Refinaria Premiun 1 no Maranhão e Abreu e Lima em Pernambuco . A Petrobras era vista como uma empresa sólida e inovadora que havia aumentado substancialmente a produção brasileira de petróleo, e sua tecnologia de exploração em águas profundas receberam diversos prêmios no setor de óleo e gás, tornando-a uma empresa de referência no setor.

Em 2012 a Valeq mudou o nome para Romão, a empresa precisava se preparar para o promissor e desafiador futuro que se colocava a sua frente, modernizando o seu maquinário e aumentando os investimentos para a certificação de seus produtos. Para isso a Romão elevou seu nível de alavancagem financeira, aumentando seu risco financeiro, mas havia grande expectativa de um significativo retorno do investimento em função dos projetos da Petrobras para a exploração do pré-sal.

Em 17 de março de 2014 foi deflagrada a operação Lava Jato, que ainda segue em curso, e que revelou um esquema de corrupção envolvendo empreiteiras, políticos e a Petrobras, que afetou profundamente a imagem e as finanças da maior empresa do país. Por outro lado, no intuito de conter a inflação, o governo não permitiu o aumento no preço da gasolina, que no Brasil estava sendo vendida abaixo do seu preço internacional, o que trouxe ainda mais prejuízos para os cofres da companhia. Nesse período também, o preço do barril do petróleo saiu de um patamar de U\$ 110,00 em janeiro, para U\$ 50,00 no final do ano.

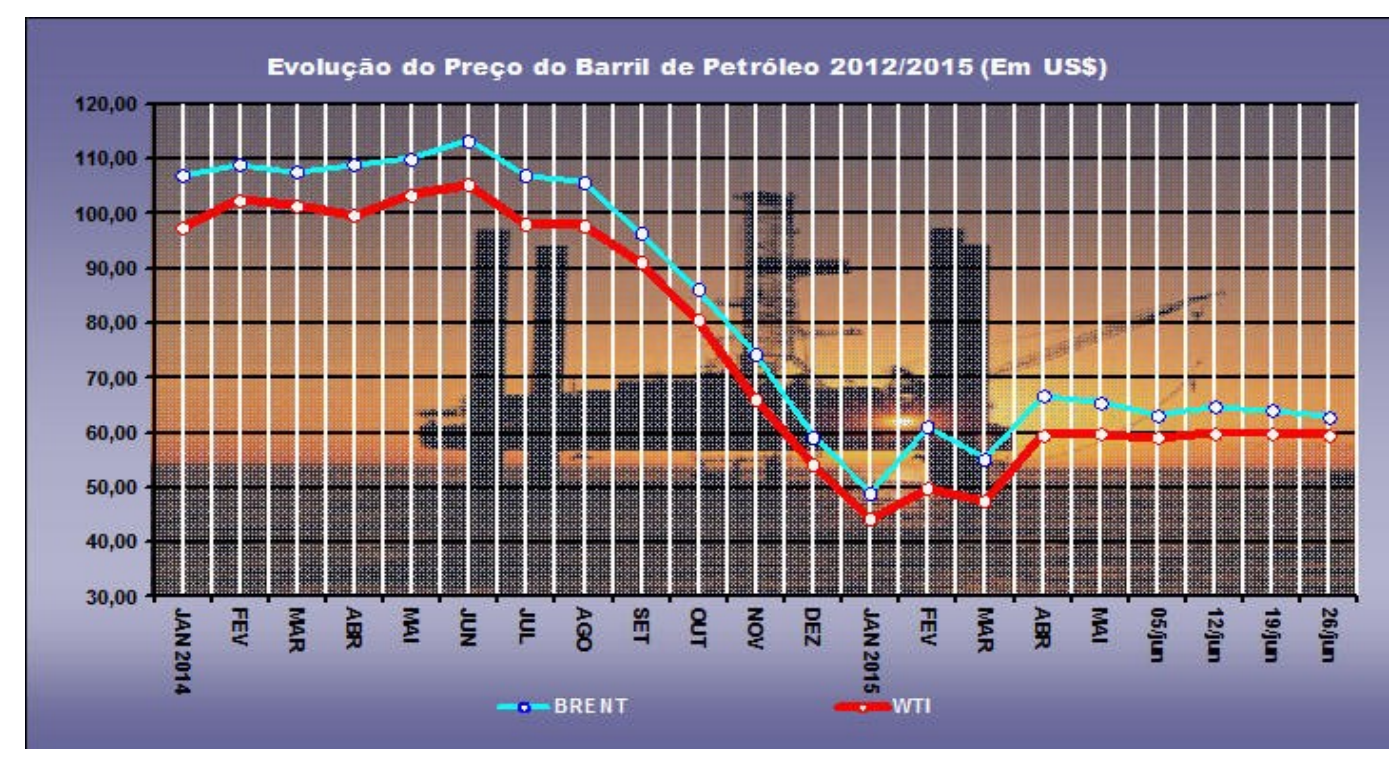

Figura 4 - Evolução do preço do barril de petróleo Fonte ANP 
No ano de 2015 a empresa viu seu faturamento cair 44\%, fechando o ano com um prejuízo de $\mathrm{R} \$ 1$ 1.529.648,00. A deterioração do ambiente político e econômico obrigou a empresa a fazer uma reestruturação completa, colocar em prática um programa de redução salarial, com ênfase na bonificação para o atingimento de metas e descentralizou uma gerência geral em três departamentos: Financeiro, Comercial e Operações. Alguns colaboradores foram demitidos, resultando em uma redução de gastos com pessoal de aproximadamente $50 \%$.

Macaé foi uma das regiões mais afetadas pela crise e o fluxo de capital para a região secou com o redimensionamento da política de investimentos divulgado pela Petrobras. A operação da Romão na região era cara e difícil de gerir em função da distância e foi tomada a decisão de aproveitar uma concessão da prefeitura de Japeri para construir a nova sede da empresa no município. Estima-se uma redução de $30 \%$ nas despesas operacionais com a mudança e outras medidas, além do incentivo fiscal, o distrito industrial de Japeri é estratégico do ponto de vista da localização, pois se encontra às margens de duas importantes vias de acesso: A rodovia BR-160, que faz a ligação dos estados do Rio e São Paulo e o Arco Metropolitano que liga os municípios de Itaboraí até Itaguaí.

Para concluir a nova sede, a empresa recorreu ao apoio da AGERIO, agência de fomento do estado do Rio de Janeiro, que emprestou o montante de $\mathrm{R} \$$ 4.425.512,00 a taxa de juros de TJLP (Taxa de juros de longo prazo) mais um por cento ao ano, que juntamente com recursos próprios, permitiu a implantação da nova sede em Japeri numa área de $7.000 \mathrm{~m} 2$ e que a Romão alcançasse o seu objetivo de nacionalizar a norma EN12874 (agora ABNT 1752) e tornar o Corta-chamas da Romão, o único no país com certificado para explosões e deflagrações.

Atualmente a Romão se depara com um cenário difícil. Apesar das mudanças no organograma e nos processos internos, que deixaram a empresa mais eficiente e comprometida com o resultado, em função dos investimentos, a empresa viu seu nível de endividamento crescer a patamares elevados, em um cenário de grandes incertezas no mercado de petróleo. As projeções apontam para anos difíceis em 2016 e 2017, com uma tímida melhora em 2018, a depender da celeridade e efetividade das mudanças politicas e econômicas que são necessárias. 


\section{Avaliação da empresa}

Nesse capítulo vamos aplicar o método de avaliação por fluxo de caixa descontado para determinar o valor da Romão. A análise ocorrida nos capítulos anteriores sobre o mercado e a empresa, permite a projeção de fluxos de caixa futuros, bem como fornece parâmetros para determinar o custo de capital da empresa. São essas duas variáveis, sustentadas pelo referencial teórico abordado no capítulo três, que fornecerão o valor da empresa, objetivo desse estudo.

\subsection{Considerações iniciais}

O regime de tributação da empresa Romão é o Lucro presumido, que é uma forma de tributação simplificada, a qual se presume o lucro, a partir da receita bruta da empresa, por ser uma aproximação do lucro, os impostos incidem sobre a receita e a empresa que possui dívida não obtém o benefício fiscal do endividamento.

\begin{tabular}{|l|c|c|}
\hline \multirow{2}{*}{$\begin{array}{c}\text { Tabela Lucro } \\
\text { Presumido }\end{array}$} & Produto & Serviço \\
\cline { 2 - 3 } & Alíquota sobre o faturamento & Alíquota sobre o faturamento \\
\hline PIS & $0,65 \%$ & $0,65 \%$ \\
\hline COFINS & $3,00 \%$ & $3,00 \%$ \\
\hline CSLL & $1,08 \%$ & $2,88 \%$ \\
\hline IRPJ & $1,20 \%$ & $4,80 \%$ \\
\hline ICMS & Variável de acordo c/ produto & - \\
\hline IPI & Variável de acordo c/ produto & - \\
\hline ISS & - & $2 \%$ a $5 \%$ \\
\hline
\end{tabular}

Tabela 2 - Tabela das alíquotas no Lucro presumido

Nas projeções de fluxo de caixa e no cálculo do custo do capital não será levado em consideração o efeito da inflação, porque será admitido que o efeito 
da inflação sobre os custos e despesas será anulado pelo efeito da inflação na receita.

\subsection{Projeção do fluxo de caixa}

Foram projetados três fluxos de caixa diferentes, considerando os cenários: pessimista, realista e otimista. O cenário base, que se encontra no item 8.7. nos anexos, para projeção foi o cenário realista e as previsões e análises são em relação ao cenário base, a partir dele foram aplicados fatores de maneira que o Lucro operacional ou EBIT (earnings before interest and tax) do cenário pessimista fosse em média $55 \%$ menor que o cenário base, para o cenário otimista o Lucro operacional ficou em média $65 \%$ maior que o cenário base, a probabilidade de cada cenário ocorrer veio com a colaboração do CEO da empresa, responsável pela estratégia e com uma experiência de 30 anos de mercado, foi estimado que o cenário realista tenha $60 \%$ de probabilidade de ocorrer, o cenário otimista $10 \%$ e o cenário pessimista $30 \%$, o que demonstra que a avaliação possui um viés mais conservador. As projeções se encontram nos anexos.

\subsubsection{Projeção da Receita}

A Romão faturou em 2015 o montante de $\mathrm{R} \$ 7.521 .534$ o seu pior resultado nos últimos três anos, para 2016 o boletim Focus do Banco Central divulgado em março projeta um recuo de 3,66\% do PIB (produto interno bruto), mas dados divulgados pela FGV (Fundação Getúlio Vargas) do índice de confiança da indústria em abril de 2016 demonstram que o setor projeta uma melhora para o segundo semestre de 2016.

$\mathrm{O} \mathrm{ICI}$ (índice de confiança da indústria) avançou 2,4 pontos e atingiu seu maior nível desde abril de 2015 
Índice de Confiança da Indústria

(dados de ago/08 a abr/16, dessazonalizados)

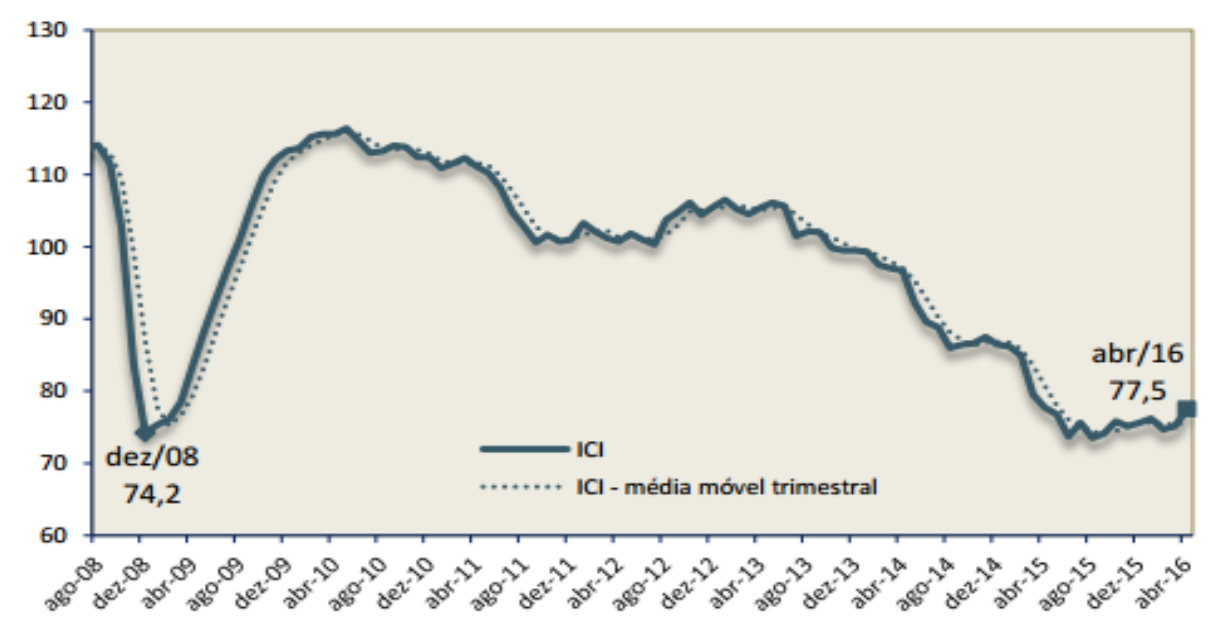

Figura 5 - Índice de confiança da indústria. Fonte: FGV

"Embora ainda insuficiente para se identificar um efetivo ponto de virada da confiança industrial, os números de abril trazem aspectos novos e favoráveis às perspectivas do setor. O Nível de Utilização da Capacidade, por exemplo, sobe de forma consistente pela primeira vez desde 2013, e as expectativas para a situação dos negócios nos seis meses seguintes são as menos pessimistas desde fevereiro de 2015. Ainda há muita ociosidade, incerteza e pessimismo, mas o setor parece enfim avistar uma luz no fim do túnel", afirma Aloisio Campelo Jr., Superintendente Adjunto para Ciclos Econômicos da FGV/IBRE

Considerando as perspectivas de melhora do setor industrial e os indicadores macroeconômicos do ministério da fazenda, a empresa projeta em 2016 um faturamento igual ao realizado em 2015.

Em 2017 a previsão é de uma tímida recuperação econômica do país, dados do boletim Focus de março apontam para um crescimento do PIB de $0,35 \%$. A Romão projeta um aumento de $20 \%$ nas vendas de produtos e $30 \%$ de serviços.

Existe uma demanda represada no setor de óleo e gás e etanol, para atingir papel de protagonismo no cenário mundial o Brasil precisa retomar os investimentos nessas duas áreas estratégicas, empreendimentos como o COMPERJ, a refinaria de Abreu e Lima e o Porto do Açu, são exemplos de um demanda represada para a empresa. A previsão é que com a melhora no ambiente econômico o ano de 2018 represente um crescimento de $40 \%$ das vendas de produto e $25 \%$ das vendas de serviço. 
Para o ano de 2019 a projeção da Romão é chegar ao mesmo patamar de faturamento de 2013, ano em que a empresa atingiu a receita recorde de aproximadamente $\mathrm{R} \$ 16$ milhões.

Em 2020 a projeção é que a empresa continue crescendo conforme suas taxas históricas, um aumento de $30 \%$ na receita de produto e $20 \%$ de serviço, atingindo um faturamento da ordem de $\mathrm{R} \$ 20$ milhões.

\subsubsection{Projeção dos custos dos produtos / serviços vendidos}

Os custos dos produtos e serviços prestados irão variar conforme a receita. A Romão possui um sistema de controle de custos para determinar as margens de seus produtos / serviços. A tabela 4 demonstra as margens por linha de produto / serviço.

\begin{tabular}{|c|c|c|c|c|c|}
\hline Margem de Contribuição & 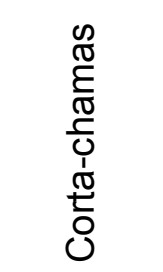 & $\underset{>}{\stackrel{1}{2}}$ & $\begin{array}{l}\frac{\pi}{\bar{J}} \\
\frac{\bar{U}}{\bar{D}} \\
\frac{0}{2} \\
\frac{0}{0} \\
\infty\end{array}$ & $\begin{array}{l}3 \\
\frac{3}{2} \\
\frac{0}{0} \\
\infty\end{array}$ & 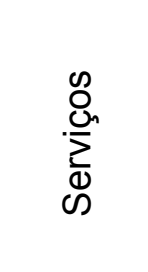 \\
\hline & $100 \%$ & $100 \%$ & $100 \%$ & $100 \%$ & $100 \%$ \\
\hline PIS & $0,65 \%$ & $0,65 \%$ & $0,65 \%$ & $0,65 \%$ & $0,65 \%$ \\
\hline COFINS & $3,00 \%$ & $3,00 \%$ & $3,00 \%$ & $3,00 \%$ & $3,00 \%$ \\
\hline CSLL & $1,08 \%$ & $1,08 \%$ & $1,08 \%$ & $1,08 \%$ & $2,88 \%$ \\
\hline IR & $1,20 \%$ & $1,20 \%$ & $1,20 \%$ & $1,20 \%$ & $4,80 \%$ \\
\hline Desoneração & $1,50 \%$ & $1,50 \%$ & $1,50 \%$ & $1,50 \%$ & $1,50 \%$ \\
\hline ISS & - & - & - & - & $5,00 \%$ \\
\hline Receita Líquida & $92,57 \%$ & $92,57 \%$ & $92,57 \%$ & $92,57 \%$ & $82,17 \%$ \\
\hline Comissão interna & $6,00 \%$ & $6,00 \%$ & $6,00 \%$ & $6,00 \%$ & $6,00 \%$ \\
\hline $\begin{array}{l}\text { Custo do } \\
\text { material/serviço }\end{array}$ & $30,00 \%$ & $36,00 \%$ & $38,00 \%$ & $43,00 \%$ & $10,00 \%$ \\
\hline $\begin{array}{l}\text { Margem de } \\
\text { contribuição }\end{array}$ & $56,57 \%$ & $50,57 \%$ & $48,57 \%$ & $43,57 \%$ & $66,17 \%$ \\
\hline
\end{tabular}

Tabela 3 - Margem dos produtos / serviço 


\subsubsection{Projeção dos Gastos com pessoal}

No final de 2015 a Romão passou por uma reestruturação, com o objetivo de cortar gastos e tornar a gestão mais profissional a empresa descentralizou a gerência geral em três gerências: Financeira, Comercial e Operações. A empresa cortou salários e reduziu a quantidade de colaboradores, essas ações projetam uma redução de 50\% dos gastos com pessoal em 2016.

Relatório divulgado pelo FMI (Fundo Monetário Internacional) em abril de 2016 prevê um índice de desemprego de 9,2\% em 2016 e 10,2\% em 2017, essa taxa diminui a pressão por aumentos salariais e a previsão é que o gasto com pessoal aumente em $20 \%$ em função do aumento da mão de obra direta de produção para fazer frente ao maior volume de vendas.

Em 2018 a previsão é que a empresa contrate mão de obra direta para acompanhar o crescimento da receita, a projeção de crescimento é de $30 \%$.

No ano de 2019 a empresa projeta igualar a receita de 2013, naquele ano o gasto com pessoal foi de $\mathrm{R} \$ 5$ milhões, mas a reestruturação da empresa, a melhoria de processos internos e o consequente aumento da produtividade fazem a empresa projetar um gasto com pessoal de aproximadamente $\mathrm{R} \$ 4$ milhões para o ano de 2019.

Em 2020 a projeção com o gasto de pessoal é de aumento de $30 \%$ em relação ao ano anterior, esse aumento representa a contratação de mão de obra qualificada e os maiores gastos com treinamento e desenvolvimento dos colaboradores para fazer frente às projeções de crescimento.

\subsubsection{Projeção das Despesas operacionais}

As despesas operacionais da demonstração de resultado da Romão não tem relação com o volume de produção, são de natureza fixa. Por isso a projeção de aumento é uma progressão aritmética de $5 \%$ a cada ano.

\subsubsection{Projeção das Despesas de venda}

Em 2015 a empresa implementou o orçamento gerencial, que determina que as despesas com venda do ano seguinte serão $5 \%$ do faturamento do ano anterior. 


\subsubsection{Projeção das Despesas financeiras e com depreciação}

A empresa fez investimentos para criação de uma nova unidade e modernização do seu maquinário, o endividamento da empresa cresceu e hoje $60 \%$ do passivo da empresa é dívida. No horizonte de cinco anos a empresa não planeja nenhum investimento em imobilizado ou captação de recursos junto aos bancos, dessa forma, a projeção das despesas financeiras e das despesas com depreciação representam as expectativas de juros e depreciação da estrutura física e financeira atual.

\subsubsection{Projeção do fluxo de caixa livre}

A partir das premissas adotadas, foram projetadas demonstrações de resultado futuras até 2020 levando-se em consideração os três cenários. Para chegar ao fluxo de caixa livre foi calculado o NOPAT (Lucro líquido operacional depois dos impostos) e adicionado à despesa com depreciação. A partir do ano 2021 o fluxo de caixa livre vai crescer a uma taxa (g) de $3,1 \%$ ao ano perpetuamente, a taxa de crescimento segue a previsão de crescimento do PIB do setor da indústria segundo projeção do Bradesco para o longo prazo, conforme item 8.9 dos anexos.

\begin{tabular}{|c|c|c|c|c|c|c|c|c|c|c|c|}
\hline \multicolumn{2}{|c|}{ Fluxo de Caixa Livre } & \multicolumn{2}{|r|}{2016} & \multicolumn{2}{|r|}{2017} & \multicolumn{2}{|r|}{2018} & 2019 & \multicolumn{2}{|r|}{2020} & \multirow[t]{2}{*}{2021} \\
\hline \multirow{5}{*}{ Pessirnista } & Lucro Liquiddo & $-\mathrm{RS}$ & 422.116 & RS & 168.128 & & 863.586 & $R \$ 1.390 .553$ & $R \$$ & 1.816 .000 & \\
\hline & (+) Despesa Financeira & $\mathrm{R} \$$ & 333.521 & $\mathrm{RS}$ & 295.451 & & 200.013 & $\begin{array}{ll}\mathrm{R} \$ & 109.922 \\
\end{array}$ & $\mathrm{RS}$ & 29.088 & \\
\hline & $\Leftrightarrow$ NOPAT & $-\mathrm{R} \$$ & 88.595 & RS & 463.579 & & 1.063 .599 & $R \$ 1.500 .475$ & $R S$ & 1.845 .087 & \\
\hline & (+) Depreciação & $\mathrm{R} \$$ & 122732 & $\mathrm{R} \$$ & 115.680 & $\mathrm{RS}$ & 115680 & RS $\quad 115.680$ & $\mathrm{RS}$ & 113.680 & \\
\hline & ( $\Rightarrow$ Fluxo de caixa Livre & $\mathrm{RS}$ & 34.137 & $\mathrm{R}$ & 579.259 & $\mathrm{R} \$$ & 1.179 .279 & RS 1.616 .155 & $\mathrm{RS}$ & 1.958 .767 & RS 2.019 .489 \\
\hline \multirow{5}{*}{ Realista } & Lucro Líquiddo & $\mathrm{RS}$ & 463.727 & $R S$ & 1.091 .128 & $\mathrm{R} \$$ & 1.802020 & $R \$ 2.276 .989$ & $R S$ & 2580.868 & \\
\hline & $(+)$ Despesa Financeira & $\mathrm{RS}$ & 333.521 & $\mathrm{RS}$ & 295.451 & & 200.013 & $\begin{array}{ll}R S & 109.922 \\
\end{array}$ & $\mathrm{RS}$ & 29.088 & \\
\hline & $\Leftrightarrow$ NOPAT & $\mathrm{RS}$ & 797.249 & RS & 1.386 .579 & $\mathrm{RS}$ & 2002033 & $\mathrm{RS} 2386.912$ & $\mathrm{RS}$ & 2609.956 & \\
\hline & (+) Depreciação & $\mathrm{RS}$ & 122.732 & RS & 115.680 & $\mathrm{RS}$ & 115680 & RS $\quad 115.680$ & $\mathrm{RS}$ & 113.680 & \\
\hline & ( $\Rightarrow$ Fluxo de caixa Livre & RS & 919.981 & Rs & 1.502 .259 & & 2.117 .713 & Rs 2.502 .592 & $\mathrm{RS}$ & 2.723 .636 & RS 2.808 .069 \\
\hline \multirow{5}{*}{ Otimista } & Lucro Liquiddo & $\mathrm{RS}$ & 1.349 .570 & RS & 2.189 .527 & $\mathrm{RS}$ & 3.375 .480 & $\mathrm{RS} 4.497 .373$ & $\mathrm{RS}$ & 5.051 .585 & \\
\hline & $(+)$ Despesa Financeira & $\mathrm{RS}$ & 333.521 & RS & 295.451 & & 200.013 & RS $\quad 109.922$ & $\mathrm{RS}$ & 29.088 & \\
\hline & $\Leftrightarrow$ NOPAT & $\mathrm{RS}$ & 1.683 .092 & RS & 2.484 .978 & & 3.575 .493 & R\$ 4.607.295 & $R \$$ & 5.080 .673 & \\
\hline & (+) Depreciação & $\mathrm{RS}$ & 122732 & $\mathrm{RS}$ & 115.680 & & 115680 & RS $\quad 115.680$ & $\mathrm{RS}$ & 113.680 & \\
\hline & ( $)$ Fluxo de caixa Livre & RS & 1.805 .824 & $\mathrm{RS}$ & 2.600 .658 & $\mathrm{RS}$ & 3.691 .173 & RS 4.722 .975 & Rs & 5.194 .353 & Rs 5.355 .378 \\
\hline
\end{tabular}

Tabela 4 - Projeção do fluxo de caixa nos 3 cenários 


\subsection{Taxa de desconto}

A taxa de desconto utilizada para trazer a valor presente é o WACC, custo médio ponderado de capital, para determinar o custo de capital da empresa, vai se considerar o custo do capital próprio, o custo do capital de terceiros e a estrutura de capital.

\subsection{1 custo do capital de terceiros}

O custo do capital de terceiros é uma média ponderada das taxas de juros dos financiamentos vigentes, a Romão possui quatro financiamentos sendo três com taxas de juros pós-fixadas indexadas pela TJLP (Taxa de juros de longo prazo), custo básico dos financiamentos concedidos pelo BNDES e um financiamento de capital de giro com taxa pré-fixada de $19,75 \%$ ao ano.

Foi considerado uma TJLP de $7,5 \%$ ao ano, conforme divulgado pelo Conselho Monetário Nacional em 31 de março.

\begin{tabular}{|c|c|c|c|c|c|}
\hline Financiamentos & Indexador & $\begin{array}{l}\text { Taxa a.a. } \% \\
\text { (A) }\end{array}$ & $\begin{array}{l}\text { \% Da dívida } \\
\text { total (B) }\end{array}$ & $(\mathrm{A}) \times(\mathrm{B})$ & $\begin{array}{l}\text { Valor presente } \\
\text { líquido }\end{array}$ \\
\hline $\begin{array}{l}\text { Banco do Brasil } 451 \\
\text { proger }\end{array}$ & TJLP+ 3,5\% & $11,00 \%$ & $2,90 \%$ & $0,32 \%$ & $\mathrm{R} \$ \quad 140.864,00$ \\
\hline $\begin{array}{l}\text { Banco do Brasil } 891 \\
\text { proger }\end{array}$ & TJLP+ 3,5\% & $11,00 \%$ & $2,04 \%$ & $0,22 \%$ & $98.839,86$ \\
\hline Agerio & TJLP+1,00\% & $8,50 \%$ & $87,10 \%$ & $7,40 \%$ & $\mathrm{R} \$ 4.225 .512,00$ \\
\hline $\begin{array}{l}\text { Bradesco Capital de } \\
\text { Giro }\end{array}$ & 19,75\% Pré & $19,75 \%$ & $7,96 \%$ & $1,57 \%$ & $\mathrm{R} \$ \quad 386.136,68$ \\
\hline $\begin{array}{l}\text { Custo do capital de } \\
\text { terceiros (Kt) }\end{array}$ & & & $100,00 \%$ & $9,52 \%$ & $\mathrm{R} \$ 4.851 .352,54$ \\
\hline
\end{tabular}

Tabela 5 - Custo do capital de terceiros (Kt)

\subsection{2 custo do capital próprio}

Para o custo do capital próprio, foi utilizado o modelo do CAPM. Esse modelo não é recomendado para países emergentes, onde o mercado de capitais é volátil e concentrado, por isso foi calculado o custo do capital próprio nos Estados Unidos, expurgado o efeito da inflação americana e incorporado o risco Brasil, chegando ao custo do capital próprio no Brasil. 


\subsubsection{Custo do capital próprio nos Estados Unidos}

O primeiro passo foi encontrar o índice Beta desalavancado $(\beta u)$, isto é, expurgado o risco do endividamento. Foi utilizado o $\beta u$ do setor de equipamentos e serviços para o mercado de óleo e gás norte americano divulgado pelo site do economista Aswath Damodaran, a tabela completa pode ser consultado no item 8.3 nos anexos.

\begin{tabular}{|l|c|c|c|c|c|}
\hline Industry Name & $\begin{array}{c}\text { Number of } \\
\text { firms }\end{array}$ & Beta & D/E Ratio & Tax rate & $\begin{array}{c}\text { Unlevered } \\
\text { beta ( } \beta \mathrm{u})\end{array}$ \\
\hline $\begin{array}{l}\text { Oilfield } \\
\text { Svcs/Equip. }\end{array}$ & 143 & 1,74 & $39,08 \%$ & $9,56 \%$ & $\mathbf{1 , 2 9}$ \\
\hline
\end{tabular}

Tabela 6 - Beta desalavancado do setor de equipamentos e serviços para o mercado de óleo e gás

A partir do beta desalavancado, foi calculado o beta alavancado $(\beta I)$ de acordo com a relação entre dívida e patrimônio líquido da Romão. No caso do regime de tributação da empresa não existe o benefício fiscal da dívida.

\begin{tabular}{|l|l|r|}
\hline \multicolumn{2}{|c|}{$\beta \mathbf{I}=\boldsymbol{\beta} \mathbf{u}$ * [1 + D/E] } \\
\hline$\beta u$ & $\begin{array}{l}\text { Beta desalavancado. Considerado o beta desalavancado histórico } \\
\text { do setor de equipamentos e serviços para o mercado de óleo e } \\
\text { gás dos Estados unidos }\end{array}$ & 1,29 \\
\hline D/E & Relação entre a dívida e o patrimônio Líquido & 3,21 \\
\hline BI & Beta alavancado. Considerado a relação D/E & $\mathbf{5 , 4 1}$ \\
\hline
\end{tabular}

Tabela 7 - Beta alavancado da Romão

Para o cálculo do custo do capital próprio nos EUA foi utilizado um prêmio de risco divulgado pelo site do economista Aswath Damodaran e a taxa livre de risco considerada foi a dos títulos do tesouro americano de longo prazo ( $T$-bonds 30 years yield) conforme item 8.4 nos anexos. 


\begin{tabular}{|l|l|r|}
\hline \multicolumn{2}{|c|}{ Ks = Rf + $\beta$ I $\mathbf{x}$ (Rm - Rf) } \\
\hline (Rm-Rf) & Prêmio de risco & $6,12 \%$ \\
\hline Rf & $\begin{array}{l}\text { Taxa livre de risco. Títulos do tesouro americana de longo } \\
\text { prazo (30 anos) - T-Bonds 30 years }\end{array}$ & $2,27 \%$ \\
\hline$\beta I$ & Beta alavancado da Romão & 5,41 \\
\hline Ks & Custo do capital Próprio nos Estados Unidos & $\mathbf{3 5 , 4 0 \%}$ \\
\hline
\end{tabular}

Tabela 8 - Custo do capital próprios nos EUA (Ks)

O custo do capital da Romão nos Estados Unidos (Ks) é de 35,40\% ao ano. Para chegar ao custo do capital próprio no Brasil é necessário expurgar o efeito da inflação norte-americana e adicionar o prêmio de risco de se investir no Brasil. O IPC (índice de preços ao consumidor) norte americano foi de 1,125\% em 2015, segundo o FED (Federal Reserve Sistem) e o prêmio de risco do Brasil foi obtido pelo site do economista Aswath Damodaran conforme item 8.5 nos anexos.

\begin{tabular}{|l|l|r|}
\hline \multicolumn{2}{|c|}{$\mathrm{Kp}=((1+\mathrm{ks}) /(1+$ I USA $)-1)+\mathrm{Rbra}$} \\
\hline Rbra & Risco Brasil & $7,23 \%$ \\
\hline I USA & inflação nos Estados Unidos & $1,125 \%$ \\
\hline Ks & custo do capital Próprio nos Estados Unidos & $35,40 \%$ \\
\hline & \multicolumn{2}{|c|}{} \\
Kp & custo do capital Próprio no Brasil & $\mathbf{4 1 , 1 3 \%}$ \\
\hline
\end{tabular}

Tabela 9 - Custo do capital próprio no Brasil

\subsubsection{Custo médio ponderado de capital (WACC)}

Para determinar o WACC empresa ponderou o custo de capital próprio e de terceiros por sua participação na estrutural de capital da empresa, chegando a um valor de $17,04 \%$ ao ano. Ressaltado que o regime tributário da empresa não oferece benefício fiscal. 


\begin{tabular}{|c|c|c|}
\hline \multicolumn{3}{|c|}{$W A C C=K t^{*}(D /(E+D))+K p^{*}(E /(E+D))$} \\
\hline $\mathrm{Kt}$ & Custo do capital de terceiros & $9,52 \%$ \\
\hline $\mathrm{Kp}$ & Custo do capital próprio & $41,13 \%$ \\
\hline $\mathrm{D}$ & Dívida da empresa & $\mathrm{R} \$ 4.851 .351,00$ \\
\hline$E$ & Patrimônio Líquido & $\mathrm{R} \$ 1.513 .645,00$ \\
\hline$(D /(E+D))$ & $\begin{array}{l}\text { Montante da dívida na estrutura de } \\
\text { capital }\end{array}$ & $76 \%$ \\
\hline$(E /(E+D))$ & $\begin{array}{l}\text { Montante do patrimônio líquido na } \\
\text { estrutura de capital }\end{array}$ & $24 \%$ \\
\hline WACC & $\begin{array}{l}\text { Custo médio ponderado de capital da } \\
\text { Romão }\end{array}$ & $17,04 \%$ \\
\hline
\end{tabular}

Tabela 10 - Custo médio ponderado de capital da Romão

\subsection{O Valor da empresa}

O valor da empresa vai ser obtido através do cálculo do valor presente dos três cenários ponderado pela probabilidade de cada cenário ocorrer menos as dívidas e mais o patrimônio não operacional da empresa.

\subsubsection{O Valor da perpetuidade}

Para calcular o valor da perpetuidade no ano 2020 nos diferentes cenários, vamos utilizar o fluxo de caixa projetado em 2021 dividido pela diferença entre a taxa de desconto (WACC) e a taxa de crescimento.

Para determinar a taxa de crescimento foi analisada a projeção de longo prazo do Bradesco divulgado em Março para a economia brasileira que aponta para uma taxa de crescimento de $3,1 \%$ ao ano na indústria a partir de 2021 .

\begin{tabular}{|c|c|c|c|c|}
\hline \multicolumn{2}{|r|}{$V P=P 1 /(R-g)$} & Pessimista & Realista & Otmista \\
\hline P1 & $\begin{array}{l}\text { Valor do fluxo de caixa onde se inicia a } \\
\text { perpetuidade. No caso o fluxo de caixa } \\
\text { correspondente ao ano } 2021\end{array}$ & $\mathrm{R} \$ \quad 2.019 .489,10$ & $\mathrm{R} \$ \quad 2.808 .068,79$ & $\mathrm{R} \$ \quad 5.355 .377,56$ \\
\hline R & Taxa de desconto. Considerado o WACC & $17,04 \%$ & $17,04 \%$ & $17,04 \%$ \\
\hline g & Taxa de crescimento & $3,10 \%$ & $3,10 \%$ & $3,10 \%$ \\
\hline VP & $\begin{array}{l}\text { Valor presente da perpetuidade. No caso o } \\
\text { valor presente no ano } 2020\end{array}$ & $\mathrm{R} \$ 14.491 .633,23$ & $\mathrm{R} \$ 20.150 .394,95$ & $\mathrm{R} \$ \mathbf{3 8 . 4 2 9 . 6 0 4 , 4 5}$ \\
\hline
\end{tabular}

\section{Tabela 11 - Valor presente da perpetuidade}




\subsubsection{O valor do fluxo de caixa projetado nos cenários}

Para encontrar o valor presente da empresa, o valor da perpetuidade vai ser adicionado ao fluxo de caixa no ano 2020 conforme tabela abaixo. O fluxo projetado dos três cenários vai ser descontado pelo custo do capital da empresa.

\begin{tabular}{|c|c|c|c|c|c|c|}
\hline Cenários & Vpl & 2016 & 2017 & 2018 & 2019 & 2020 \\
\hline Pessimista & 9.540 .940 & 34.137 & 579.259 & 1.179 .279 & 1.616 .155 & 16.450 .401 \\
\hline Realista & 14.955 .006 & 919.981 & 1.502 .259 & 2.117 .713 & 2.502 .592 & 22.874 .031 \\
\hline Otimista & 28.128 .718 & 1.805 .824 & 2.600 .658 & 3.691 .173 & 4.722 .975 & 43.623 .957 \\
\hline $\begin{array}{l}\text { Taxa de desconto } \\
\text { (WACC) }\end{array}$ & & $17,04 \%$ & & & & \\
\hline
\end{tabular}

Tabela 12 - VPL da empresa nos três cenários

O valor da empresa considerado o cenário pessimista é de aproximadamente $\mathrm{R} \$ 9$ milhões e considerado o cenário otimista $\mathrm{R} \$ 28$ milhões, o valor no cenário base é de $R \$ 15$ milhões. Para chegar ao valor provável da empresa vamos ponderar os valores obtidos pela probabilidade de cada cenário.

\begin{tabular}{|l|c|c|c|}
\hline \multicolumn{1}{|c|}{ Cenários } & Probabilidade $(\mathrm{A})$ & $\mathrm{VPL}(\mathrm{B})$ & $(\mathrm{A}) \times(\mathrm{B})$ \\
\hline Pessimista & $30 \%$ & $\mathrm{R} \$ 9.540 .940$ & $\mathrm{R} \$ 2.862 .282$ \\
\hline Realista & $60 \%$ & $\mathrm{R} \$ 14.955 .006$ & $\mathrm{R} \$ 8.973 .004$ \\
\hline Otimista & $10 \%$ & $\mathrm{R} \$ 28.128 .718$ & $\mathrm{R} \$ 2.812 .872$ \\
\hline $\begin{array}{l}\text { Valor provável da empresa considerado os 3 } \\
\text { cenários }\end{array}$ & $\mathrm{R} \$ 14.648 .158$ \\
\hline
\end{tabular}

Tabela 13 - Valor da empresa considerado a probabilidade de cada cenário

\subsubsection{O Valor líquido da empresa}

O valor da empresa considerados os três cenários e suas probabilidades é de $\mathrm{R} \$ 14.684 .158$, mas a empresa possui dívidas com seus credores e possui um terreno em Macaé que não é utilizado para sua atividade fim. Portanto o valor líquido da Romão é o valor presente de seus fluxos de caixa menos suas dívidas mais seu ativo não operacional 


\begin{tabular}{|l|c|}
\hline \multicolumn{1}{|c|}{ Valor provável da empresa } & $\mathrm{R} \$ 14.648 .157$ \\
\hline (-) Total de dívidas & $-\mathrm{R} \$ 4.851 .351$ \\
\hline (+) Total de Ativos não operacionais & $\mathrm{R} \$ 1.000 .000$ \\
\hline (=) Valor Líquido da empresa Romão & $\mathbf{R} \$ 10.796 .806$ \\
\hline
\end{tabular}

Tabela 14 - Valor líquido da empresa

O valor final da Romão líquido de dívidas, considerados os três cenários e suas probabilidades é de $\mathrm{R} \$ 10.796 .806$. 


\section{Conclusão e Recomendação}

No início do trabalho foi feita uma contextualização do mercado de petróleo e seus derivados e do mercado sucroenergético. A Romão atua em um nicho de mercado comum a esses dois mercados, a segurança da operação no armazenamento dos fluidos.

O mercado de óleo e gás se caracteriza por um alto grau de exigibilidade técnica e de segurança, os produtos e serviços seguem normas internacionais e possuem maior valor agregado, o que atrai competidores globais, como é o caso dos principais concorrentes da Romão como a alemã Protego, ou a americana Growth. Esses players atuam no mundo todo, possuem produtos certificados e investem em pesquisa e desenvolvimento.

O mercado sucroenergético passa por uma transição. Seguidas safras ruins, intervenção no preço da gasolina e a maior dificuldade de crédito subsidiado, fez com que grande parte das usinas falisse. Investidores externos, principalmente ligados ao setor de óleo e gás, pressionados por fontes alternativas mais limpas de energia, estão aproveitando o momento de ativos depreciados, para adquirir essas usinas. O mercado está convergindo para as características do mercado de óleo e gás, aumentando sua exigência técnica e de segurança.

A Romão acompanhou a tendência do mercado, construiu o primeiro laboratório de ensaios para deflagração e detonação do Brasil, certificou sua linha de corta-chamas e hoje é a única empresa nacional apta a fornecer esses equipamentos. A empresa se prepara para aumentar sua participação no competitivo mercado de óleo e gás. O câmbio desvalorizado, e a política de conteúdo local, são as principais oportunidades. Em contrapartida a dificuldade de caixa da Petrobras, a baixa atividade econômica e a queda do preço do barril do petróleo são ameaças que afetam o resultado da empresa.

Essa combinação de diversos fatores, políticos, sociais e econômicos influencia na projeção do fluxo de caixa da empresa e demonstra o quão volátil e arriscado é o negócio da Romão, o que explica a diferença entre o valor da 
empresa no cenário pessimista de $\mathrm{R} \$ 9.540 .940$ e no cenário otimista de $\mathrm{R} \$$ 28.128.718.

Contudo, é tarefa dos gestores analisar o micro e macro ambiente para elaborar estratégias com objetivos de maximização do valor. Em função do risco do negócio, é recomendável que a empresa diminua sua alavancagem financeira, buscando uma estrutura de capital menos exposta às variações na taxa de juros, a diminuição da alavancagem operacional também deve ser um foco de atuação na tentativa de reduzir os custos fixos e ficar menos exposto a sazonalidade da demanda, gastos com pesquisa e desenvolvimento devem ser mantidos ou ampliados e as despesas com venda devem priorizar o treinamento e capacitação de vendedores para venda direta, dado a complexidade do produto oferecido.

A empresa também deve avaliar a venda de ativos para fortalecer seu caixa, buscar a renegociação de financiamentos com melhores taxas ou alongamento da dívida e aproveitar a moeda desvalorizada para exportar seus produtos, principalmente para os vizinhos do Mercosul.

O objetivo do trabalho de determinar um valor para a empresa Romão foi atingido, o valor líquido final de $\mathrm{R} \$ 10.796 .806$ corresponde ás expectativas dos acionistas e está alinhado com a realidade do mercado, comparando a aquisição da ASCA, empresa de São Paulo de mesmo porte, que atua em mercado similar, vendida para um grupo estrangeiro por quinze milhões de reais em 2010, segundo informações fornecidas pelo próprio dono da ASCA ao CEO da Romão. Conclui-se também que a empresa possui potencial de valorização ou depreciação a depender das variáveis do mercado e das decisões dos gestores. 


\section{Referências Bibliográficas}

Agência Nacional de Petróleo. Anuário estatístico brasileiro do petróleo, gás natural e biocombustíveis. Rio de janeiro, 2015. Disponível em <www.anp.gov.br> Acesso em 13 de abril de 2016.

Banco Nacional de Desenvolvimento Econômico e Social. Perspectivas do investimento 2015-2018 e panoramas setoriais. São Paulo, 2014. Disponível em <.web.bndes.gov.br> Acesso em 13 de abril de 2016.

Bradesco. Projeções Bradesco de Longo Prazo. São Paulo, 2016. Disponível em <. http://www.economiaemdia.com.br> Acesso em 15 de maio de 2016.

BREALEY, R. MEYER, S. ALLEN, F. Princípios de finanças corporativas. Porto Alegre: MC Graw Haill, 2008.

COPELAND, T. KOLLER, T. MURRIN, J. Avaliação de Empresas Valuation. São Paulo: Makron books, 2004.

DAMODARAN, A. Avaliação de empresas. São Paulo: Pearson, 2007.

DAVIS, E. POINTON, J. Finance and the Firm. Oxford: Oxford University Press, 1996.

Fundação Getúlio Vargas. Sondagens e índices de confiança. São Paulo, 2016. Disponível em < http://portalibre.fgv.br> Acesso em 15 de maio de 2016.

Instituto Brasileiro de Petróleo. Dados do setor 2015. Rio de Janeiro, 2016. Disponível em <.http://www.ibp.org.br> Acesso em 15 de maio de 2016.

NEVES, M. TROMBIM, V. A dimensão do setor sucroenergético. Ribeirão Preto: USP, 2014.

ROSS, A. WESTERFIELD, R. JORDAN, B. Fundamentos de Administração Financeira. Porto Alegre: MC Graw Haill, 2010.

TITMAN, S. MARTINS, J. Avaliação de projetos e investimentos. São Paulo: Brookman, 2010. 


\section{Anexos}

\subsection{Demonstrações de Resultado}

\begin{tabular}{|c|c|c|c|c|c|c|c|c|c|c|c|c|}
\hline \multirow[b]{2}{*}{ Demonstração de Resultado } & \multicolumn{4}{|c|}{2013} & \multicolumn{4}{|c|}{2014} & \multicolumn{4}{|c|}{2015} \\
\hline & & 옳 & & $\sum_{\infty}^{\circ}$ & & $\frac{0}{\frac{7}{0}}$ & & $\sum_{\substack{\infty \\
\infty}}^{\circ}$ & & 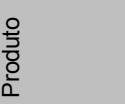 & & 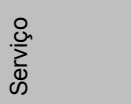 \\
\hline Receita Bruta & $\mathbf{R} \$$ & 9.326 .184 & $\mathbf{R} \mathbf{S}$ & 6.846 .132 & $\mathbf{R} \mathbf{S}$ & 5.398 .047 & $R \$$ & 8.564 .057 & R\$ & 3.198 .892 & $\mathbf{R} \$$ & 4.322 .642 \\
\hline PIS & $-R \$$ & 60.620 & $-\mathrm{R} \$$ & 44.500 & $-\mathrm{R} \$$ & 35.087 & $-R \$$ & 55.666 & $-R \$$ & 20.793 & $-\mathrm{R} \$$ & 28.097 \\
\hline COFINS & $-\mathrm{R} \$$ & 279.786 & $-\mathrm{R} \$$ & 205.384 & $-R \$$ & 161.941 & $-R \$$ & 256.922 & $-\mathrm{R} \$$ & 95.967 & $-\mathrm{R} \$$ & 129.679 \\
\hline Desoneração & $-R \$$ & 93.262 & $-R \$$ & 68.461 & $-R \$$ & 53.980 & $-R \$$ & 85.641 & $-R \$$ & 31.989 & $-\mathrm{R} \$$ & 43.226 \\
\hline ISS & $\mathrm{R} \$$ & - & $-\mathrm{R} \$$ & 342.307 & $\mathrm{R} \$$ & - & $-\mathrm{R} \$$ & 428.203 & $\mathrm{R} \$$ & - & $-\mathrm{R} \$$ & 216.132 \\
\hline Receita Líquida & $\mathbf{R} \$$ & 8.892 .517 & $\mathbf{R} \$$ & 6.185 .480 & $\mathbf{R} \$$ & 5.147 .038 & $\mathrm{R} \$$ & 7.737 .625 & $\mathrm{R} \$$ & 3.050 .144 & $\mathbf{R} \$$ & 3.905 .507 \\
\hline Comissão interna & $-R \$$ & 559.571 & $-\mathrm{R} \$$ & 410.768 & $-\mathrm{R} \$$ & 323.883 & $-R \$$ & 513.843 & $-R \$$ & 191.934 & $-\mathrm{R} \$$ & 259.359 \\
\hline Custo do material/serviço direto de produg & $-R \$$ & 2.797 .855 & $\mathrm{R} \$$ & & $-\mathrm{R} \$$ & 1.619 .414 & $\mathrm{R} \$$ & & $-R \$$ & 959.668 & $\mathrm{R} \$$ & \\
\hline Custo do material/ servico indireto de prod & $\mathrm{R} \$$ & & $-\mathrm{R} \$$ & 684.613 & $\mathrm{R} \$$ & . & $-R \$$ & 856.406 & $\mathrm{R} \$$ & 0 & $-\mathrm{R} \$$ & 432.264 \\
\hline Margem de contribuição & $\mathrm{R} \$$ & 5.535 .090 & $\mathrm{R} \$$ & 5.090 .099 & $\mathrm{R} \$$ & 3.203.741 & $\mathrm{R} \$$ & 6.367 .376 & $\mathrm{R} \$$ & 1.898 .542 & $R \$$ & 3.213 .884 \\
\hline Lucro Bruto & $\mathbf{R} \$$ & & & 10.625 .190 & $\mathbf{R} \mathbf{S}$ & & & 9.571 .117 & R\$ & & & 5.112 .427 \\
\hline Gastos com pessoal & $-R \$$ & & & 5.097 .587 & $-R \$$ & & & 4.358 .348 & $-\mathrm{R} \$$ & & & 4.182 .970 \\
\hline Despesasoperacional & $-R \$$ & & & 2.153 .784 & $-R \$$ & & & 2.437 .638 & $-\mathrm{R} \$$ & & & 1.060 .378 \\
\hline \begin{tabular}{|l} 
Despesas de venda \\
\end{tabular} & $-\mathrm{R} \$$ & & & 169.158 & $-R \$$ & & & 390.420 & $-\mathrm{R} \$$ & & & 42.742 \\
\hline Despesas com depreciação & $-R \$$ & & & 122.732 & $-R \$$ & & & 122.732 & $-\mathrm{R} \$$ & & & 122.732 \\
\hline Lucro operacional & $\mathrm{R} \$$ & & & 3.081 .929 & R\$ & & & 2.261 .979 & $-\mathrm{R} \$$ & & & 296.395 \\
\hline Despesa financeira & $-R \$$ & & & 278.824 & $-\mathrm{R} \$$ & & & 316.849 & $-R \$$ & & & 475.274 \\
\hline LAIR & $\mathbf{R} \$$ & & & 2.803 .105 & R\$ & & & 1.945 .130 & $-R S$ & & & 771.669 \\
\hline Despesa com imposto de renda & $-\mathrm{R} \$$ & & & 934.043 & $-\mathrm{R} \$$ & & & 898.639 & $-\mathrm{R} \$$ & & & 462.563 \\
\hline Despesa com CSLL & $-R \$$ & & & 297.891 & $-\frac{T Q}{-R S}$ & & & 304.944 & 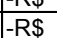 & & & $\frac{40.003}{159.040}$ \\
\hline $\begin{array}{l}\text { Lucro Líquido } \\
\end{array}$ & $\mathbf{R} \$$ & & & 1.571 .170 & $\mathbf{R} \$$ & & & 741.548 & $-\mathrm{R} \$$ & & & 1.393 .272 \\
\hline
\end{tabular}


8.2. Balanço Patrimonial 2015

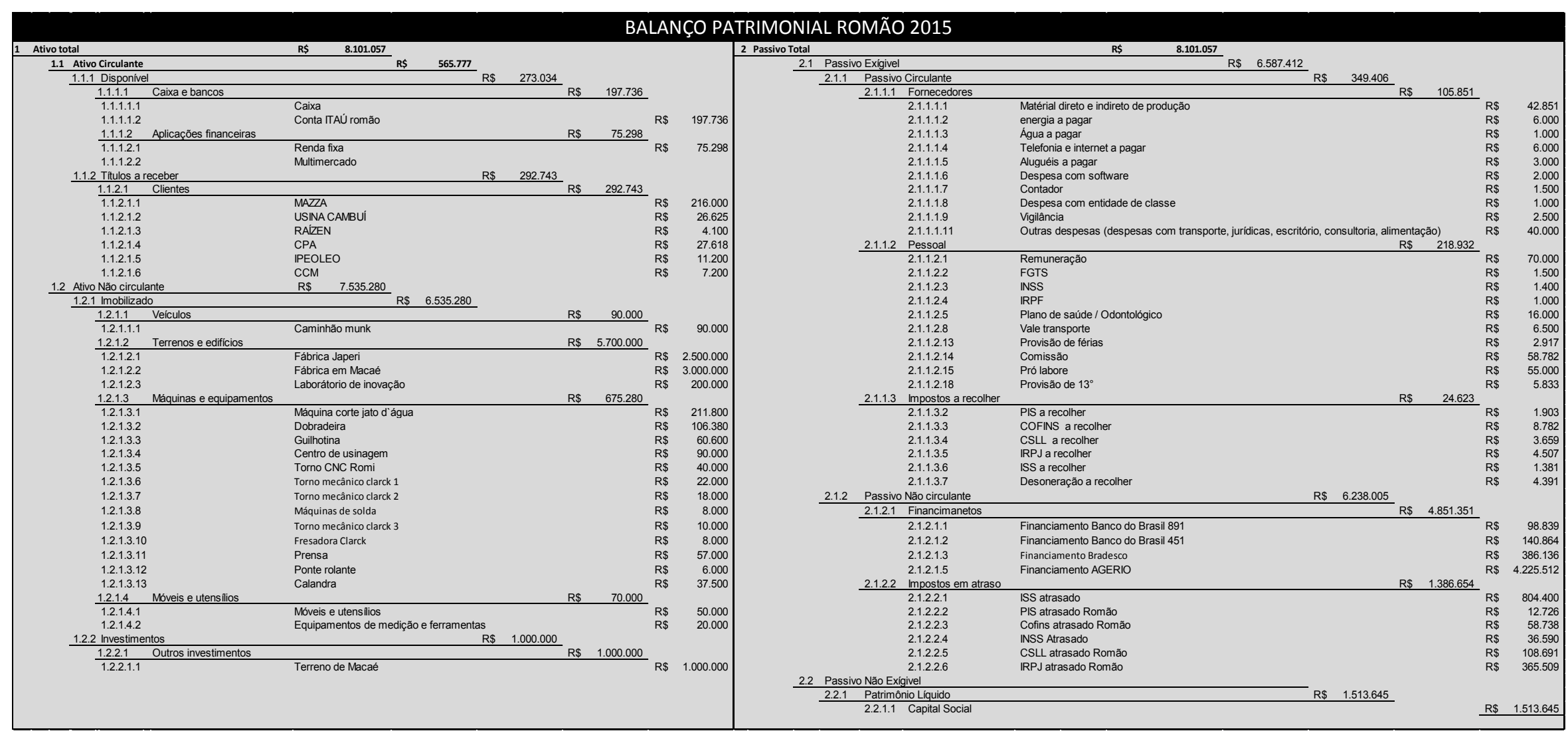


8.3. Beta desalavancado do setor (Dados do site do economista Answath Damodaran, janeiro/2016)

\begin{tabular}{|c|c|c|c|c|c|c|}
\hline Industry Name & $\nabla$ & Number of firms $\nabla$ & Beta & D/E Ratio $\vee$ & Tax rate $\nabla$ & Unlevered beta \\
\hline Oil/Gas (Integrated) & & 7 & 1,54 & $16,50 \%$ & $8,14 \%$ & 1,33 \\
\hline Oil/Gas (Production and Exploration) & & 351 & 1,63 & $82,48 \%$ & $2,91 \%$ & 0,91 \\
\hline Oilfield Svcs/Equip. & & 143 & 1,74 & $39,08 \%$ & $9,56 \%$ & 1,29 \\
\hline Packaging \& Container & & 25 & 1,26 & $54,73 \%$ & $21,41 \%$ & 0,88 \\
\hline Paper/Forest Products & & 20 & 1,52 & $89,06 \%$ & $15,88 \%$ & 0,87 \\
\hline Precious Metals & & 113 & 1,29 & $50,03 \%$ & $1,60 \%$ & 0,87 \\
\hline Publshing \& Newspapers & & 39 & 1,45 & $49,57 \%$ & $13,67 \%$ & 1,01 \\
\hline R.E.I.T. & & 221 & 0,76 & $89,81 \%$ & $2,17 \%$ & 0,41 \\
\hline Real Estate (Development) & & 21 & 1,41 & $62,89 \%$ & $1,06 \%$ & 0,87 \\
\hline Real Estate (General/Diversified) & & 12 & 1,22 & $25,47 \%$ & $9,64 \%$ & 0,99 \\
\hline Real Estate (Operations \& Services) & & 55 & 1,50 & $64,54 \%$ & $11,19 \%$ & 0,95 \\
\hline Recreation & & 65 & 0,91 & $31,61 \%$ & $11,33 \%$ & 0,71 \\
\hline Restaurant/Dining & & 83 & 0,76 & $25,85 \%$ & $18,54 \%$ & 0,63 \\
\hline Retail (Automotive) & & 26 & 1,06 & $53,16 \%$ & $21,18 \%$ & 0,75 \\
\hline Retail (Building Supply) & & 5 & 1,47 & $18,73 \%$ & $23,18 \%$ & 1,29 \\
\hline Retail (Distributors) & & 83 & 1,22 & $60,34 \%$ & $16,42 \%$ & 0,81 \\
\hline
\end{tabular}


8.4. Prêmio de risco e taxa livre de risco (Dados do site do economista Answath Damodaran, janeiro/2016)

\begin{tabular}{|c|c|c|c|c|}
\hline \multirow{2}{*}{ Year } & T.Bond Rate & Bond-Bill & Analyst Growth Estima & Implied Premium (FCFI' \\
\hline 2008 & $2,21 \%$ & $0,62 \%$ & $4,00 \%$ & $6,43 \%$ \\
\hline 2009 & $3,84 \%$ & $3,70 \%$ & $7,20 \%$ & $4,36 \%$ \\
\hline 2010 & $3,29 \%$ & $3,16 \%$ & $6,95 \%$ & $5,20 \%$ \\
\hline 2011 & $1,88 \%$ & $1,85 \%$ & $7,18 \%$ & $6,01 \%$ \\
\hline 2012 & $1,76 \%$ & $1,71 \%$ & $5,27 \%$ & $5,78 \%$ \\
\hline 2013 & $3,04 \%$ & $2,97 \%$ & $4,28 \%$ & $4,96 \%$ \\
\hline 2014 & $2,17 \%$ & $2,12 \%$ & $5,58 \%$ & $5,78 \%$ \\
\hline 2015 & $\mathbf{2 , 2 7} \%$ & $2,06 \%$ & $5,55 \%$ & $\mathbf{6 , 1 2 \%}$ \\
\hline
\end{tabular}

8.5.0 Risco Brasil (Dados do site do economista Answath Damodaran, janeiro/2016)

\begin{tabular}{|l|l|c|c|}
\hline Country & Africa & Moody's rating & Country Risk Premium \\
\hline Bahamas & Caribbean & Baa2 & NA \\
\hline Bahrain & Middle East & Baa3 & $4,90 \%$ \\
\hline Bangladesh & Asia & Ba3 & NA \\
\hline Barbados & Caribbean & B3 & NA \\
\hline Belarus & Eastern Europe \& Russia & Caa1 & NA \\
\hline Belgium & Western Europe & Aa3 & $0,45 \%$ \\
\hline Belize & Central and South America & Caa2 & NA \\
\hline Bermuda & Caribbean & A1 & NA \\
\hline Bolivia & Central and South America & Ba3 & NA \\
\hline Bosnia and Herzegovina & B3 & NA \\
\hline Botswana & A2 & NA \\
\hline Brazil & Africa & Baa3 & $\mathbf{7 , 2 3 \%}$ \\
\hline
\end{tabular}




\section{6 . Projeção de resultado - Cenário pessimista}

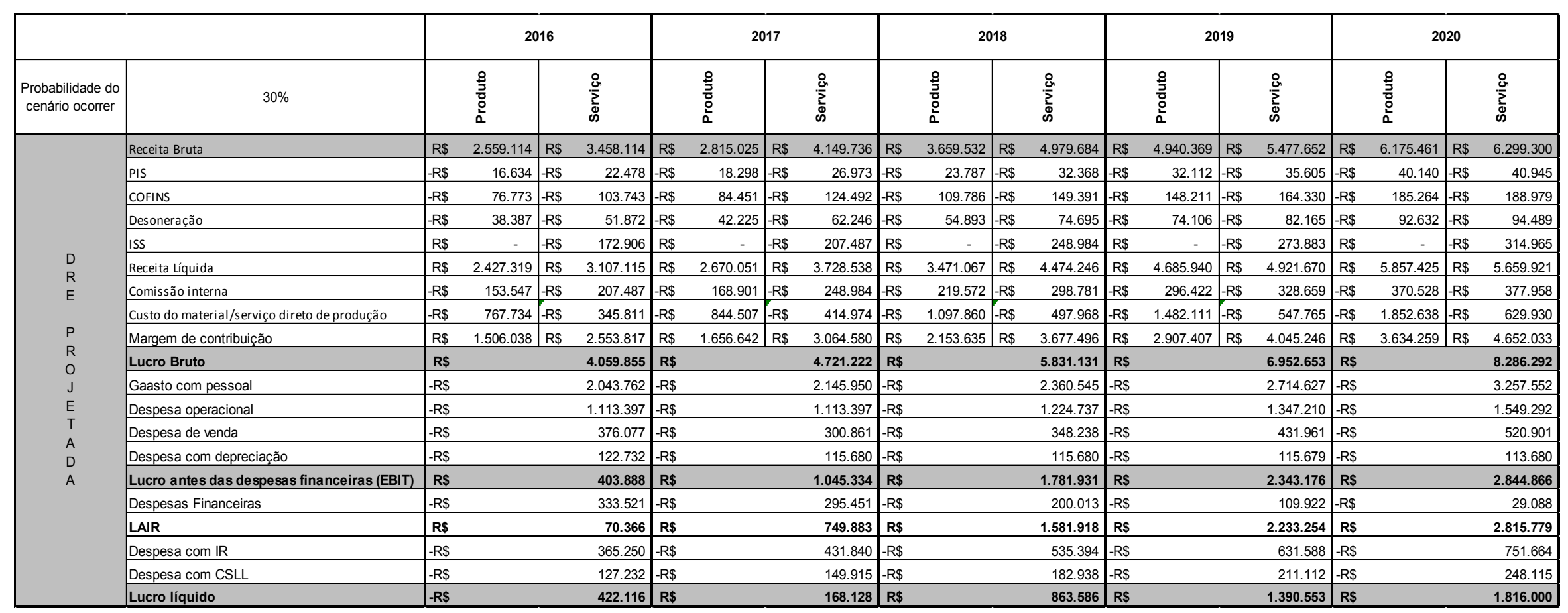




\subsection{Projeção de resultado - Cenário Realista (Cenário Base)}

\begin{tabular}{|c|c|c|c|c|c|c|c|c|c|c|c|c|c|c|c|c|c|c|c|c|c|}
\hline $\begin{array}{l}\text { Probabilidade } \\
\text { do cenário } \\
\text { ocorrer }\end{array}$ & $60 \%$ & & $\begin{array}{l}\stackrel{2}{3} \\
\stackrel{3}{0} \\
\frac{0}{2}\end{array}$ & & 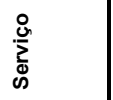 & & $\begin{array}{l}\stackrel{2}{5} \\
\frac{3}{0} \\
\frac{0}{2}\end{array}$ & & : & & $\begin{array}{l}\frac{9}{3} \\
\frac{3}{0} \\
\frac{0}{2}\end{array}$ & & : & & $\begin{array}{l}\stackrel{9}{5} \\
\stackrel{5}{0} \\
\frac{0}{2}\end{array}$ & & $\sum_{\substack{0 \\
\infty}}^{\circ}$ & & $\begin{array}{l}\frac{0}{3} \\
\stackrel{3}{0} \\
\stackrel{0}{2}\end{array}$ & & 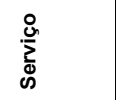 \\
\hline \multirow{8}{*}{$\begin{array}{l}D \\
R \\
E\end{array}$} & Receita Bruta & $\mathrm{R} \$$ & 3.198.892 & $\mathrm{R} \$$ & 4.322.642 & $\mathrm{R} \$$ & 3.838 .670 & $\mathrm{R} \$$ & 5.619 .435 & $\mathrm{R} \$$ & 5.374 .139 & $\mathrm{RS}$ & 7.024.293 & $\mathrm{R} \$$ & 7.523 .794 & $\mathrm{R} \$$ & 8.429 .152 & $\mathrm{R} \$$ & 9.780 .932 & $\mathrm{RS}$ & 10.114 .982 \\
\hline & PIS & $-R \$$ & 20.793 & $-R \$$ & 28.097 & $-R \$$ & 24.951 & $-R \$$ & 36.526 & $-R \$$ & 34.932 & $-R \$$ & 45.658 & $-R \$$ & 48.905 & $-R \$$ & 54.789 & $-R \$$ & 63.576 & $-R S$ & 65.747 \\
\hline & COFINS & $-R \$$ & 95.967 & $-R \$$ & 129.679 & $-R \$$ & 115.160 & $-R \$$ & 168.583 & $-R \$$ & 161.224 & $-R \$$ & 210.729 & $-R S$ & 225.714 & $-R S$ & 252.875 & $-R \$$ & 293.428 & $-R \$$ & 303.449 \\
\hline & DESONERAÇÃO & $-R \$$ & 47.983 & $-R \$$ & 64.840 & $-R \$$ & 57.580 & $-R \$$ & 84.292 & $-R \$$ & 80.612 & $-R \$$ & 105.364 & $-R S$ & 112.857 & $-R \$$ & 126.437 & $-R \$$ & 146.714 & $-R \$$ & 151.725 \\
\hline & ISS & $\mathrm{R} \$$ & - & -R\$ & 216.132 & $\mathrm{R} \$$ & - & $-R \$$ & 280.972 & $\mathrm{R} \$$ & 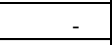 & -R\$ & 351.215 & $\mathrm{RS}$ & - & $-\mathrm{R} \$$ & 421.458 & $\mathrm{R} \$$ & - & $-R \$$ & 505.749 \\
\hline & Receita Ĺquida & $\mathrm{R} \$$ & 3.034 .149 & $\mathrm{R} \$$ & \begin{tabular}{|l|}
3.883 .894 \\
\end{tabular} & $\mathrm{R} \$$ & 3.640 .979 & $\mathrm{R} \$$ & $\begin{array}{l}5.049 .062 \\
\end{array}$ & $\mathrm{R} \$$ & 5.097 .370 & $\mathrm{R} \$$ & 6.311 .327 & $\mathrm{RS}$ & 7.136 .319 & $\mathrm{R} \$$ & 7.573 .593 & $\mathrm{R} \$$ & 9.277 .214 & $\mathrm{R} \$$ & 9.088 .312 \\
\hline & Comissão interna & $-R \$$ & 191.934 & $-R \$$ & 259.359 & $-R \$$ & 230.320 & $-R \$$ & 337.166 & $-R \$$ & 322.448 & $-R \$$ & 421.458 & $-R \$$ & 451.428 & $-R \$$ & 505.749 & $-R \$$ & 586.856 & $-R \$$ & 606.899 \\
\hline & Custo do material/serviço direto de produção & $-R \$$ & 959.668 & $-R \$$ & 432.264 & $-R \$$ & 1.151.601 & $-R \$$ & 561.943 & $-R \$$ & 1.612.242 & $-R \$$ & 702.429 & $-R S$ & 2.257 .138 & $-R \$$ & 842.915 & $-R \$$ & 2.934 .280 & $-R \$$ & 1.011 .498 \\
\hline \multirow{12}{*}{$\begin{array}{l}P \\
R \\
O \\
J \\
E \\
T \\
A \\
D \\
A\end{array}$} & Margem de contribuição & $\mathrm{R} \$$ & 1.882 .548 & $\mathrm{R} \$$ & 3.192 .271 & $\mathrm{R} \$$ & 2.259 .058 & $\mathrm{R} \$$ & 4.149.952 & $R \$$ & 3.162 .681 & $\mathrm{R} \$$ & 5.187 .441 & $\mathrm{R} \$$ & 4.427 .753 & $\mathrm{R} \$$ & 6.224 .929 & $\mathrm{R} \$$ & 5.756 .079 & $\mathrm{R} \$$ & 7.469 .914 \\
\hline & Lucro Bruto & $\mathbf{R} \$$ & & & 5.074 .819 & $\mathrm{R} \$$ & & & 6.409 .010 & R\$ & & & 8.350 .121 & $R \$$ & & & 10.652 .681 & R\$ & & & 13.225.993 \\
\hline & Gaasto com pessoal & $-R \$$ & & & 2.043 .762 & $-R \$$ & & & 2.452 .515 & $-R S$ & & & 3.188 .269 & $-R S$ & & & 4.304 .163 & $-R S$ & & & 5.595 .412 \\
\hline & Despesa operacional & $-R \$$ & & & 1.113 .397 & $-R \$$ & & & 1.280 .406 & $-R S$ & & & 1.536 .488 & $-R \$$ & & & 1.920 .610 & $-R \$$ & & & 2.496 .793 \\
\hline & Despesa de venda & $-R \$$ & & & 376.077 & $-R \$$ & & & 376.077 & $-R \$$ & & & 472.905 & $-R \$$ & & & 619.922 & $-\mathrm{R} \$$ & & & 797.647 \\
\hline & Despesa com depreciação & $-R \$$ & & & 122.732 & $-R \$$ & & & 115.680 & $-R \$$ & & & 115.680 & $-R \$$ & & & 115.680 & $-\mathrm{R} \$$ & & & 113.680 \\
\hline & Lucro antes das despesas financeiras (EBIT & R\$ & & & 1.418 .851 & R\$ & & & 2.184.332 & $\mathrm{R} \$$ & & & 3.036 .779 & R\$ & & & 3.692 .307 & $\mathbf{R} \$$ & & & 4.222.461 \\
\hline & Despesas Financeiras & $-R \$$ & & & 333.521 & $-R \$$ & & & 295.451 & $-R S$ & & & 200.013 & $-R \$$ & & & 109.922 & $-R \$$ & & & 29.088 \\
\hline & LAIR & $\mathrm{R} \$$ & & & 1.085 .330 & $\mathrm{R} \$$ & & & 1.888 .881 & R\$ & & & 2.836 .766 & RS & & & 3.582 .385 & $\mathrm{R} \$$ & & & 4.193.374 \\
\hline & Despesa com IR & $-R \$$ & & & 462.563 & $-R \$$ & & & 594.456 & $-\mathrm{R} \$$ & & & 774.406 & $-R \$$ & & & 981.379 & $-\mathrm{RS}$ & & & 1.215 .560 \\
\hline & Despesa com CSLL & $-R \$$ & & & 159.040 & $-R \$$ & & & 203.297 & $-R S$ & & & 260.340 & $-R \$$ & & & 324.017 & $-R \$$ & & & 396.946 \\
\hline & Lucro líquido & R\$ & & & 463.727 & $\mathrm{R} \$$ & & & 1.091 .128 & RS & & & 1.802 .020 & RS & & & 2.276 .989 & $\mathrm{R} \$$ & & & 2.580 .868 \\
\hline
\end{tabular}




\subsection{Projeção de resultado - Cenário Otimista}

\begin{tabular}{|c|c|c|c|c|c|c|c|c|c|c|c|c|c|c|c|c|c|c|c|c|c|}
\hline \multirow[b]{2}{*}{$\begin{array}{c}\text { Probabilidade } \\
\text { do cenário } \\
\text { ocorrer }\end{array}$} & \multirow[b]{2}{*}{$10 \%$} & \multicolumn{4}{|c|}{2016} & \multicolumn{4}{|c|}{2017} & \multicolumn{4}{|c|}{2018} & \multicolumn{4}{|c|}{2019} & \multicolumn{4}{|c|}{2020} \\
\hline & & & $\begin{array}{l}\frac{0}{3} \\
\frac{3}{0} \\
\frac{0}{2}\end{array}$ & & 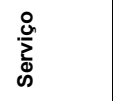 & & $\begin{array}{l}\frac{9}{3} \\
\frac{3}{0} \\
\frac{0}{2}\end{array}$ & & 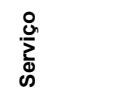 & & $\begin{array}{l}\stackrel{\circ}{5} \\
\frac{5}{0} \\
\stackrel{0}{0}\end{array}$ & & 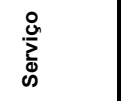 & & $\begin{array}{l}\stackrel{\circ}{5} \\
\frac{5}{0} \\
\frac{0}{0}\end{array}$ & & 迹 & & $\begin{array}{l}\frac{9}{2} \\
\frac{7}{0} \\
\frac{0}{2}\end{array}$ & & 这 \\
\hline \multirow{8}{*}{$\begin{array}{l}D \\
R \\
E\end{array}$} & Receita Bruta & RS & 3.838 .670 & $\mathrm{R} \$$ & 5.187 .170 & RS & 4.990 .272 & $R \$$ & 6.743 .322 & $R \$$ & 7.235 .894 & $R \$$ & 8.766 .318 & $\mathrm{R} \$$ & 10.130.251 & $\mathrm{R} \$$ & 11.396 .213 & $R \$$ & 13.675 .839 & $R \$$ & 13.675 .456 \\
\hline & PIS & $-R \$$ & 24.951 & $-R \$$ & 33.717 & $-R \$$ & 32.437 & $-R \$$ & 43.832 & $-R \$$ & 47.033 & $-R \$$ & 56.981 & $-R \$$ & 65.847 & $-R \$$ & 74.075 & $-R \$$ & 88.893 & $-R \$$ & 88.890 \\
\hline & COFINS & $-R \$$ & 115.160 & $-R S$ & 155.615 & $-R \$$ & 149.708 & $-R \$$ & 202.300 & $-R \$$ & 217.077 & $-R \$$ & 262.990 & $-R \$$ & 303.908 & $-R \$$ & 341.886 & $-R \$$ & 410.275 & $-R \$$ & 410.264 \\
\hline & DESONERAÇÃO & $-R \$$ & 57.580 & $-R \$$ & 77.808 & $-R \$$ & 74.854 & $-R \$$ & 101.150 & $-R \$$ & 108.538 & $-R \$$ & 131.495 & $-R \$$ & 151.954 & $-R \$$ & 170.943 & $-R \$$ & 205.138 & $-R \$$ & 205.132 \\
\hline & ISS & $\mathrm{R} \$$ & & $-R \$$ & 259.359 & $\mathrm{RS}$ & - & $-R \$$ & 337.166 & $R \$$ & - & $-R \$$ & 438.316 & $R \$$ & - & $-R \$$ & 569.811 & $R \$$ & - & $-R \$$ & 683.773 \\
\hline & Receita Líquida & $\mathrm{R} \$$ & 3.640 .979 & $\mathrm{R} \$$ & 4.660 .673 & $\mathrm{RS}$ & 4.733.273 & $R \$$ & 6.058 .874 & $R \$$ & 6.863 .245 & $R \$$ & $\begin{array}{r}7.876 .537 \\
\end{array}$ & $\mathrm{R} \$$ & 9.608 .543 & $\mathrm{R} \$$ & 10.239 .498 & $\mathrm{R} \$$ & 12.971.533 & $R \$$ & 12.287 .397 \\
\hline & Comissão interna & $-R \$$ & 230.320 & $-R \$$ & 311.230 & $-R \$$ & 299.416 & $-R \$$ & 404.599 & $-R \$$ & 434.154 & $-R \$$ & 525.979 & $-R \$$ & 607.815 & $-R \$$ & 683.773 & $-R \$$ & 820.550 & $-R \$$ & 820.527 \\
\hline & Custo do material/serviço direto de produção & $-R \$$ & 1.151.601 & $-R \$$ & 518.717 & $-R S$ & 1.497 .081 & $-R \$$ & 674.332 & $-R \$$ & 2.170 .768 & $-R \$$ & 876.632 & $-R \$$ & 3.039 .075 & $-R \$$ & 1.139 .621 & $-R \$$ & 4.102.752 & $-R \$$ & 1.367 .546 \\
\hline \multirow{12}{*}{$\begin{array}{l}\mathrm{P} \\
\mathrm{R} \\
\mathrm{O} \\
\mathrm{J} \\
\mathrm{E} \\
\mathrm{T} \\
\mathrm{A} \\
\mathrm{D} \\
\mathrm{A}\end{array}$} & Margem de contribuição & RS & 2.259 .058 & $\mathrm{RS}$ & 3.830 .725 & RS & 2.936 .775 & $R \$$ & 4.979 .943 & $R \$$ & 4.258 .323 & $\mathrm{RS}$ & 6.473 .926 & $R \$$ & 5.961 .653 & $\mathrm{RS}$ & 8.416 .104 & $\mathrm{R} \$$ & 8.048 .231 & $R \$$ & 10.099.324 \\
\hline & Lucro Bruto & R\$ & & & 6.089 .783 & R\$ & & & 7.916 .718 & R\$ & & & 10.732 .249 & $R \$$ & & & 14.377.756 & R\$ & & & 18.147.556 \\
\hline & Gaasto com pessoal & $-R \$$ & & & 2.043 .762 & $-R \$$ & & & 2.656 .891 & $-R \$$ & & & 3.719 .647 & $-R \$$ & & & 5.393 .488 & $-R \$$ & & & 7.550 .884 \\
\hline & Despesa operacional & $-R \$$ & & & 1.113.397 & $-R \$$ & & & 1.224 .737 & $-R \$$ & & & 1.408 .447 & $-R \$$ & & & 1.690 .136 & $-R \$$ & & & 2.112 .671 \\
\hline & Despesa de venda & $-R \$$ & & & 376.077 & $-R \$$ & & & 451.292 & $-R \$$ & & & 586.680 & $-R \$$ & & & 800.111 & $-R \$$ & & & 1.076 .323 \\
\hline & Despesa com depreciação & $-R \$$ & & & 122.732 & $-R \$$ & & & 115.680 & $-R \$$ & & & 115.680 & $-R \$$ & & & 115.680 & $-R \$$ & & & 113.680 \\
\hline & Lucro antes das despesas financeiras & $R \$$ & & & 2.433 .815 & $R \$$ & & & 3.468.118 & $\mathrm{R} \$$ & & & 4.901 .795 & $R \$$ & & & 6.378 .341 & R\$ & & & 7.293 .998 \\
\hline & Despesas Financeiras & $-R \$$ & & & 333.521 & $-R \$$ & & & 295.451 & $-R \$$ & & & 200.013 & $-R \$$ & & & 109.922 & $-R \$$ & & & 29.088 \\
\hline & LAIR & $R \$$ & & & 2.100 .294 & R\$ & & & 3.172.667 & $\mathrm{R} \$$ & & & 4.701.782 & $R \$$ & & & 6.268.419 & R\$ & & & 7.264.911 \\
\hline & Despesa com $\mathbb{R}$ & $-R \$$ & & & 559.875 & $-R \$$ & & & 735.038 & $-R \$$ & & & 995.685 & $-R \$$ & & & 1.333 .428 & $-R \$$ & & & 1.671 .773 \\
\hline & Despesa com CSLL & $-R \$$ & & & 190.848 & $-R \$$ & & & 248.103 & $-\mathrm{R} \$$ & & & 330.618 & $-R \$$ & & & 437.618 & $-R \$$ & & & 541.552 \\
\hline & Lucro líquido & RS & & & 1.349 .570 & RS & & & 2.189 .527 & R\$ & & & 3.375 .480 & R\$ & & & 4.497 .373 & RS & & & 5.051 .585 \\
\hline
\end{tabular}


8.9. Projeção do Bradesco de longo prazo para economia Brasileira

\section{TiT Bradesco Cenário-Longo Prazo}

\begin{tabular}{|c|c|c|c|c|c|c|c|c|c|c|c|c|c|c|c|}
\hline & 2009 & 2010 & 2011 & 2012 & 2013 & 2014 & 2015 & $2016^{*}$ & $2017^{*}$ & $2018^{*}$ & $2019^{*}$ & $2020^{*}$ & $2021^{*}$ & $2022^{*}$ & $2023^{*}$ \\
\hline Crescimento Real do PIB (\% aa.) & $-0,1$ & 7,5 & 3,9 & 1,9 & 3,0 & 0,1 & $-3,8$ & $-3,5$ & 1,5 & 3,0 & 3,5 & 3,5 & 3,5 & 3,5 & 3,5 \\
\hline Agropecuária (\%) & $-3,7$ & 6,7 & 5,6 & $-3,1$ & 8,4 & 0,4 & 1,8 & 2,0 & 2,5 & 3,5 & 3,5 & 3,5 & 3,5 & 3,5 & 3,5 \\
\hline Indústria (\%) & $-4,7$ & 10,2 & 4,1 & $-0,7$ & 2,2 & $-1,2$ & $-6,2$ & $-5,0$ & 2,5 & 4,0 & 3,1 & 3,1 & 3,1 & 3,1 & 3,1 \\
\hline Serviços (\%) & 2,1 & 5,8 & 3,4 & 2,9 & 2,8 & 0,7 & $-2,7$ & $-3,5$ & 1,0 & 2,5 & 3,6 & 3,6 & 3,6 & 3,6 & 3,6 \\
\hline PIB Nominal (R\$ bilhões) & 3.333 & 3.886 & 4.374 & 4.806 & 5.316 & 5.687 & 6.121 & 6.385 & 6.908 & 7.557 & 8.267 & 9.044 & 9.894 & 10.824 & 11.842 \\
\hline População - milhões & 193,5 & 195,5 & 197,4 & 199,2 & 201,0 & 202,8 & 204,5 & 206,1 & 207,7 & 209,2 & 210,7 & 212,1 & 213,4 & 214,7 & 216,0 \\
\hline PIB per capita - R\$ & 17.221 & 19.877 & 22.157 & 24.121 & 26.446 & 28.048 & 29.938 & 30.982 & 33.267 & 36.124 & 39.243 & 42.644 & 46.355 & 50.404 & 54.823 \\
\hline Vendas no varejo - Restrita (\%) & 5,9 & 10,9 & 6,7 & 8,4 & 4,3 & 2,2 & $-4,2$ & $-3,4$ & 0,9 & 3,5 & 4,5 & 4,5 & 4,5 & 4,5 & 4,5 \\
\hline Produção Industrial (\%) & $-7,1$ & 10,2 & 0,4 & $-2,3$ & 2,0 & $-3,3$ & $-8,3$ & $-5,6$ & 1,9 & 4,0 & 3,1 & 3,1 & 3,1 & 3,1 & 3,1 \\
\hline Taxa de desemprego (\% - média) & 8,1 & 6,7 & 6,0 & 5,5 & 5,4 & 4,8 & 6,8 & 10,2 & 8,9 & 8,5 & 8,0 & 7,5 & 7,0 & 6,3 & 6,3 \\
\hline Taxa de Crescimento da Massa Salarial - IBGE (\%) & 3,9 & 7,4 & 5,1 & 6,3 & 2,5 & 2,7 & $-5,1$ & $-1,8$ & 2,2 & 3,0 & 3,3 & 3,8 & 3,8 & 3,1 & 3,1 \\
\hline Rendimento médio real - IBGE (\%) & 3,2 & 3,8 & 3,0 & 4,1 & 1,8 & 2,7 & $-3,7$ & 0,4 & 1,0 & 1,2 & 1,5 & 2,0 & 2,0 & 2,0 & 2,0 \\
\hline
\end{tabular}




\subsection{Organograma da Romão}

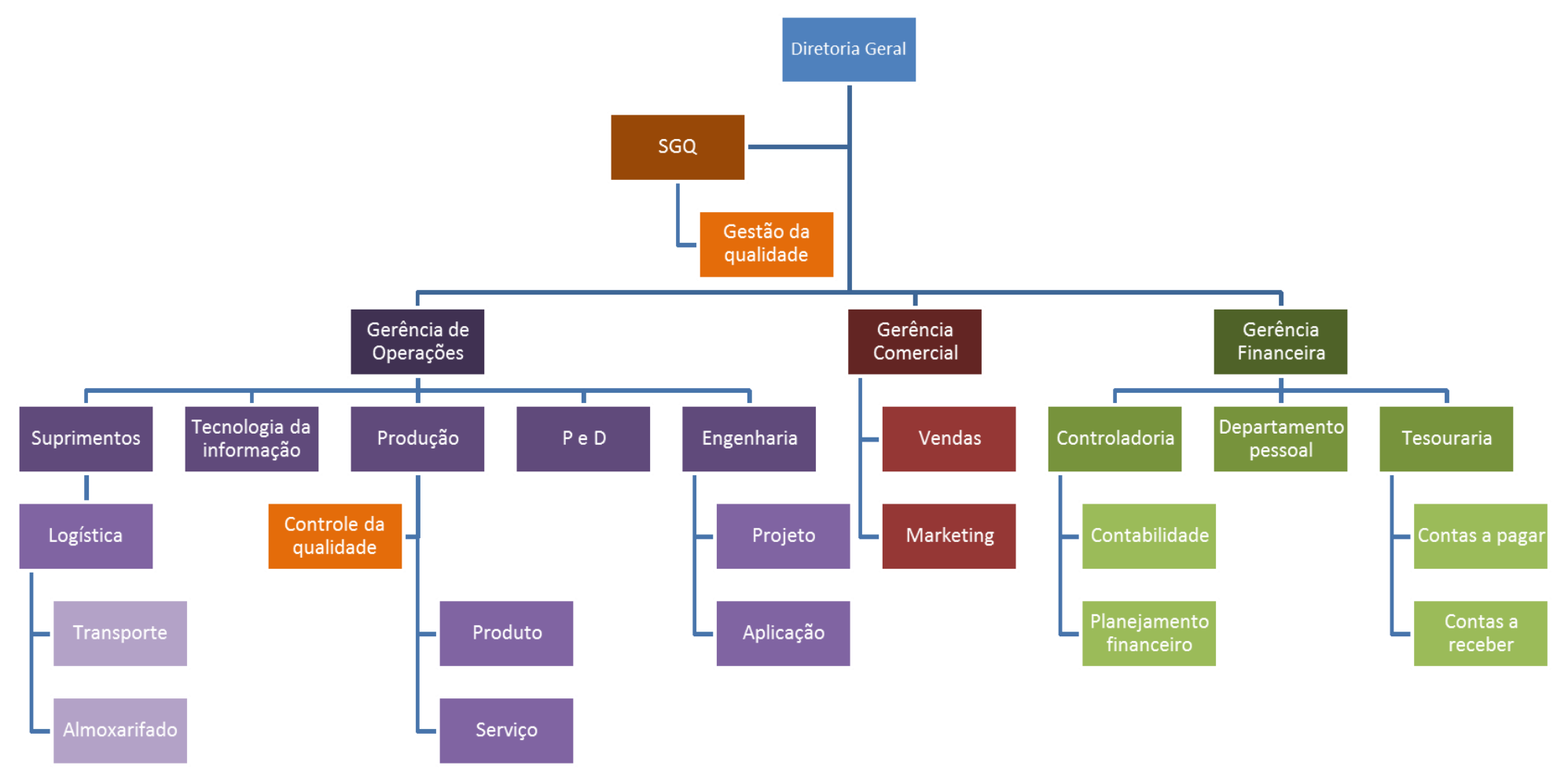




\subsection{Infraestrutura de produção e movimentação do petróleo e seus derivados}

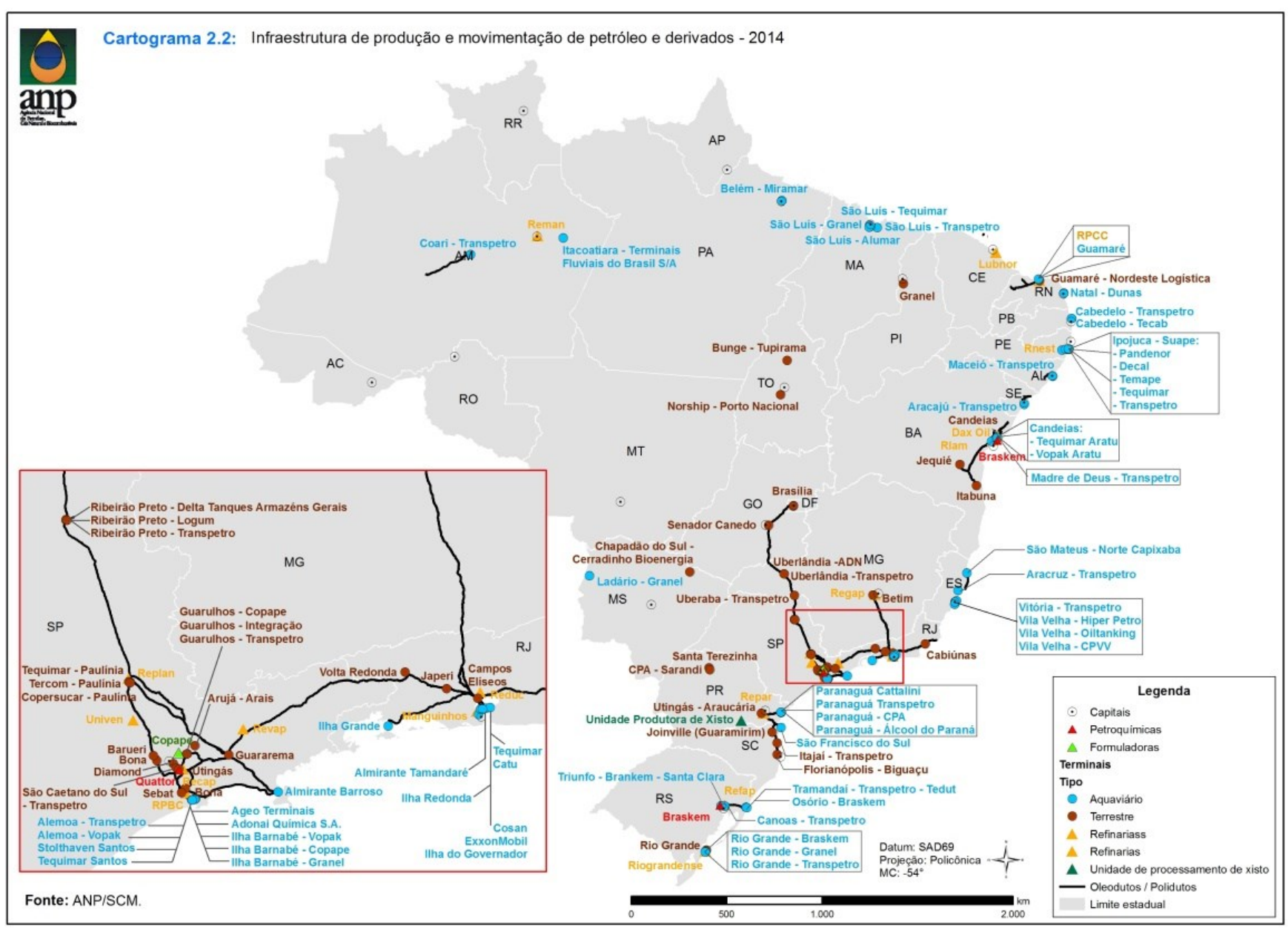




\subsection{Produtos Romão}

\section{Equipamento Corta-Chama}

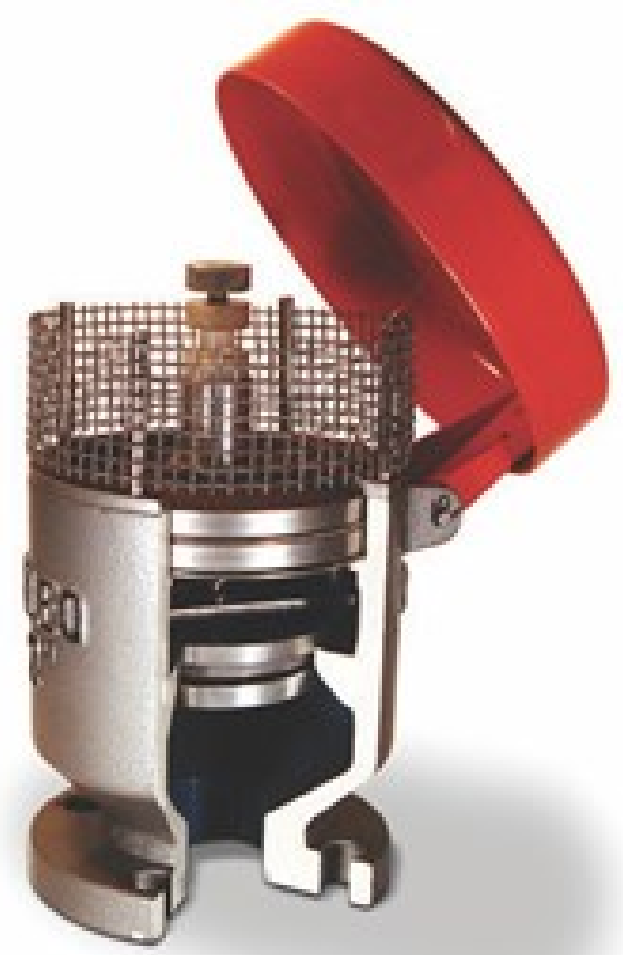

Selo Película

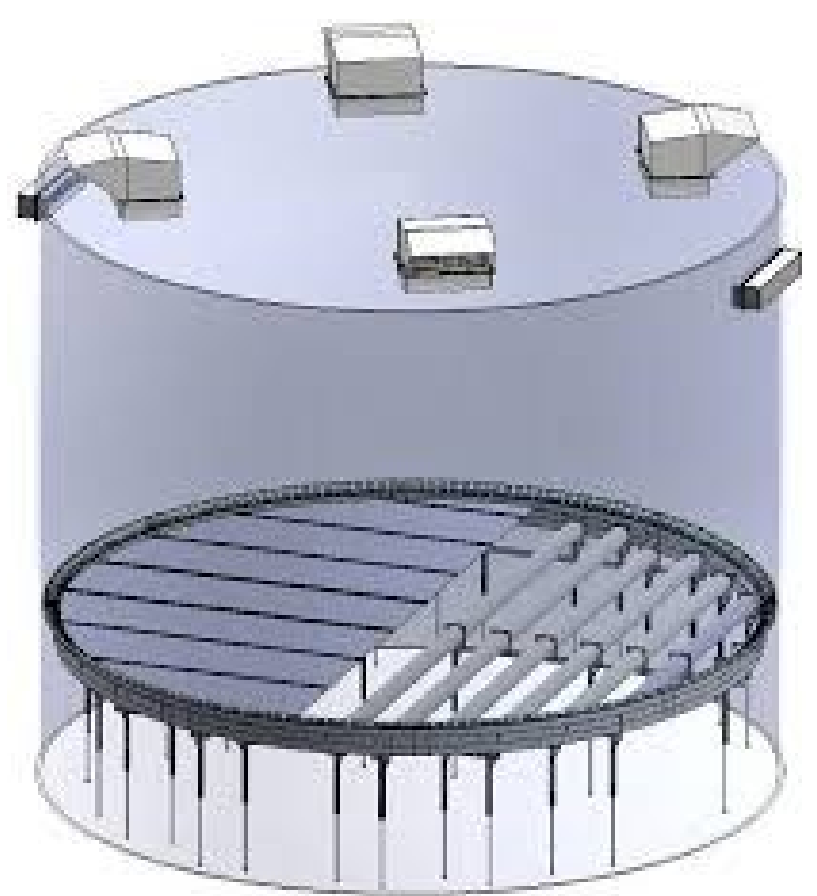

